\title{
التباين المكانيّ للشذوذِ الحراري في العرلقِ
}

الباحث صدام رزاق عبود أ.م.د مالك ناصر عبود الكناني

كلية التربية/ جامعة واسط

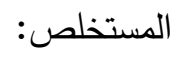

يهدف البحث إلى الكثف عن طبيعة التباين المكاني للثذوذ الحراري في العراق على المستويين

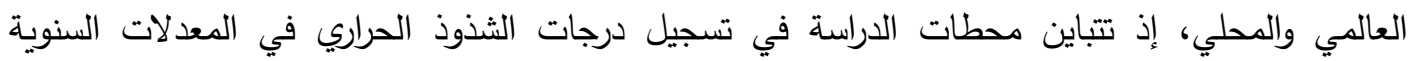

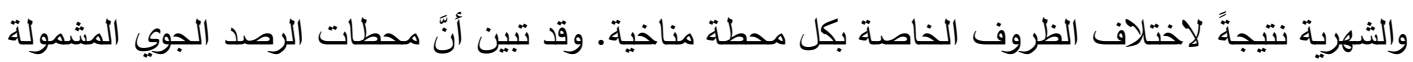

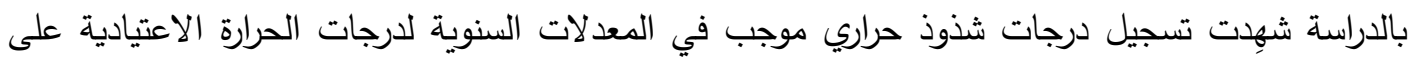

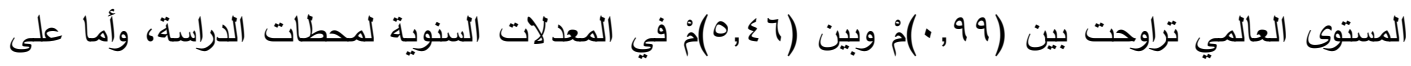

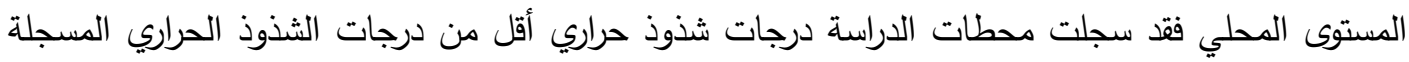

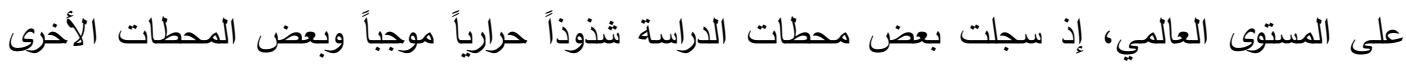
سجلت شذوذاً حرارياً سالباً في المعدلات السنوية. كلمات مفتاحية:( الشذوذ الحراري، مناخ العراق) 


\title{
Spatial variation of thermal anomalies in Iraq
}

\author{
Dr. Malik Naser Al-kinani
}

\section{Saddam Razak Abboud}

\section{: Abstract}

The aim of the research is to reveal the spatial variance of Iraq's thermal anomalies at the global and local level. The stations differ in the recording of the degrees of thermal anomalies in the annual and monthly rates due to different conditions of each station. It has been shown that the weather stations covered by the study have recorded positive global warming temperatures at a global temperatures ranging from $(0.99-5.46) \mathrm{c}$, in the annual rates of the stations. At the local level, the results of the study recorded degrees of thermal anomalies less than the degrees of anomalies at the global level, as some study stations recorded positive thermal anomalies and some climatic stations recorded negative thermal anomalies in the annual rates the monthly rates.

Keywords: (Thermal anomaly, Climate of Iraq) 
يقصد بالثذوذ الحراري الفرق بين معدل درجة حرارة مكان ما ومعدل درجة حرارة دائرة العرض التي

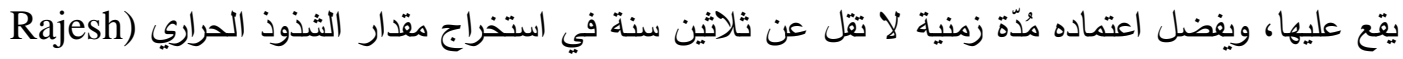

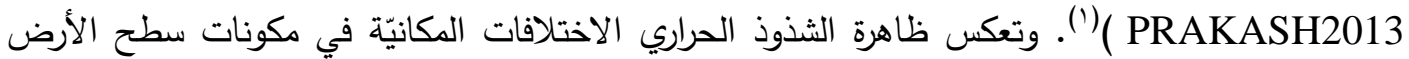

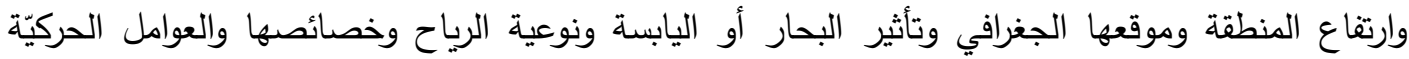

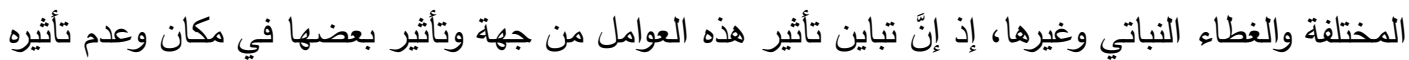

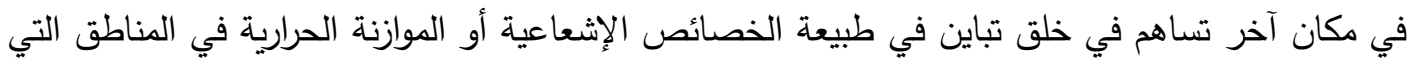

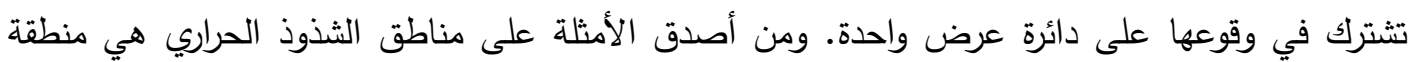

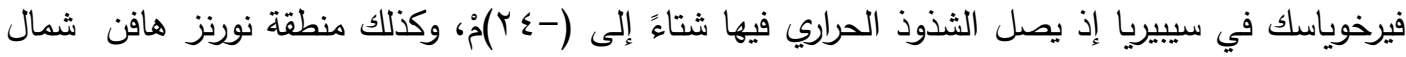

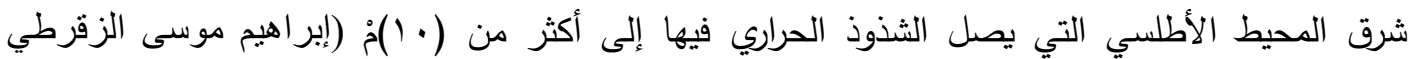
${ }^{(r)}(r \cdot . V$ أولاً: الإطار النظري:

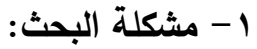

يمكن صياغة مشكلة البحث الرئيسة بالتساؤل العلمي الآتي:

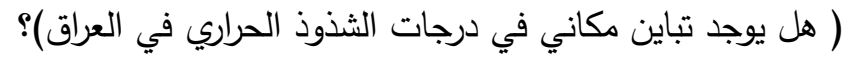

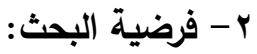

هنالك تباين مكاني للشذوذ الحراري في العراق نتيجة تباين مجموعة من الضوابط المناخية بين محطات

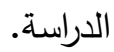

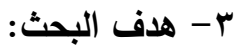
يهدف البحث إلى الكثف عن طبيعة الثذوذ الحراري في العراق، والتباين الدكاني والزماني للرجات الشذوذ الحراري بين محطات الرصد الجوي المشمولة بالدراسة. 


$$
\text { צ - تنظيم البحث: - n }
$$

تطرق البحث أولاً إلى مشكلة البحث وفرضيته وهدف البحث وتتظيمه، و ثانياً إلى التباين الدكاني للشذوذ

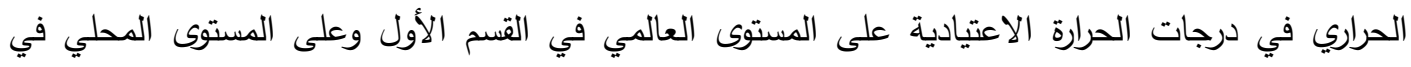

$$
\text { ه- القسم الثاني. }
$$

تتمثل الحدود المكانية لمنطقة الدراسة بجمهورية العراق إذ يقع جغرافياً في الجزء الجنوبي الغربي من قارة

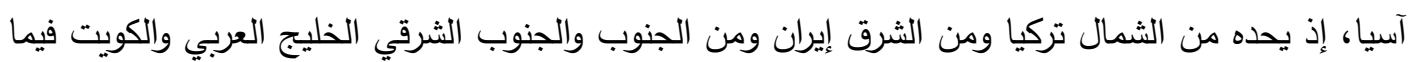

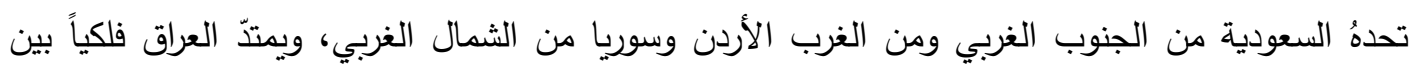

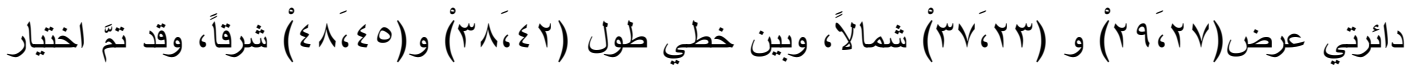

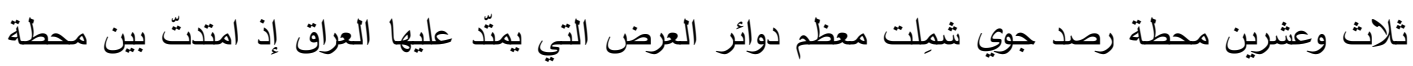

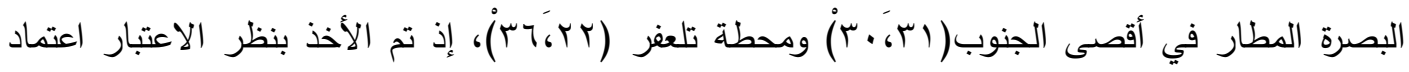
محطتين على الأقل فوق كل دائرة عرض لغرض استخراج المعدل الحراري لكل دائرة عرض في العراق.

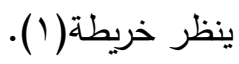




\section{خريطة( )}

التوزيع الجغر افي لمحطات الرصد الجوي في منطقة الدراسة

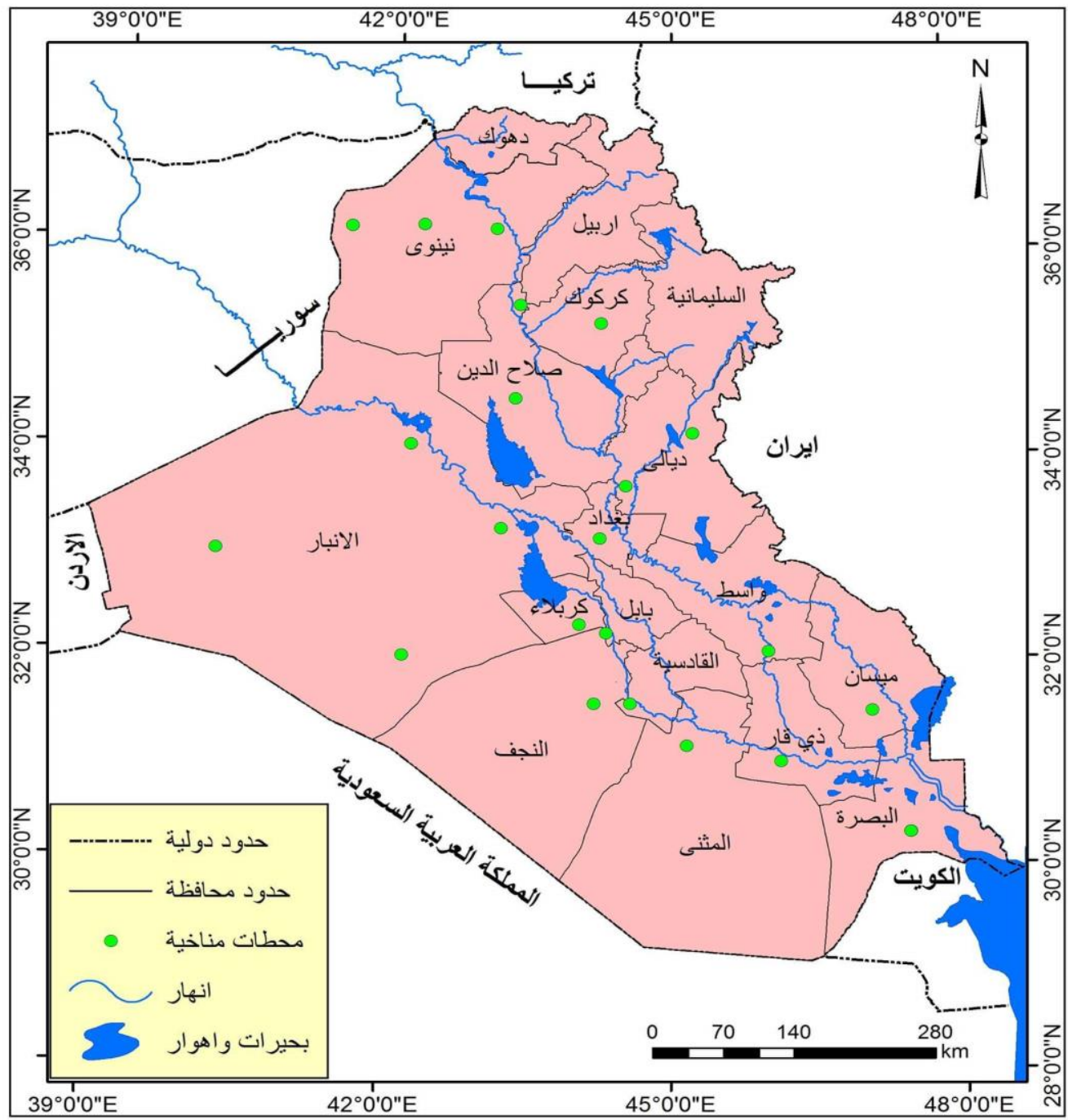

المصدر : عمل الباحث اعتماداً على:

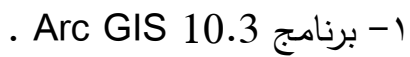


العـــــــد الثلاثون

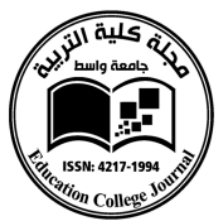

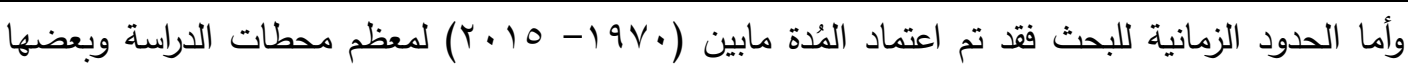
أقل من هذه المُدة لاختلاف مُدد التسجيل المناخي من جهة، ولتعرضها للإنقطاعات لأسباب مختلفة من جهة

ثانياً: الشذوذ الحراري في معدلات درجات الحرارة الاعتيادية في العرلق: تُجل محطات الرصد الجوي المشمولة بالدراسة شذوذاً حرارياً في المعدل السنوي والمعدلات الشهرية للرجة الحرارة الاعتيادية وعلى المستوين العالمي والمحلي، وقد تباينت هذه المحطات في تسجيل درجات الثذوذ الحراري إذ سجلت جميع المحطات شذوذاً حرارياً موجباً على المستوى العالمي، فيما كانت درجات الثذوذ المسجلة على المستوى المحلي متباينة بين محطات الدراسة إذ سجلت بعضها شذوذاً حرارياً موجباً و يسجل بعضها الأخر شذوذاً حرارياً سالباً. وللكشف عن طبيعة الاختلافات المكانية للشذوذ الحراري في دوائر العرض المختلفة في العراق، فقد استوجب التحليل العلمي للدراسة الكثف عن طبيعة درجات الحرارة لمحطات الدراسة مع معدلات درجات الحرارة لدوائر العرض التي تقع عليها على المستويين العالمي إذ تمّ اعتماد المعدلات الحرارية السنوية لدوائر العرض التي تشترك بها محطات الرصد الجوي في العراق، والمحلي إذ تمَّ استخراج معدل حراري لكل دائرة عرض في العراق ومقارنةً واقع المحطات مع معدلات الحرارة المحلية.

\section{1- التحليل المناخي للشذوذ الحراري في العراق على المستوى العالمي:}

تُبين المعدلات الحرارية السنوية لدرجات الحرارة الاعتيادية المسجلة في محطات الرصد الجوي المشمولة بالدراسة الحالة الحرارية في هذه المحطات، إذ تشهد جميع محطات الدراسة تسجيل معدلات حرارية سنوية مرتفعة نتج عنها معدلات حرارية لكل دائرة عرض في العراق تفوق تلك المعدلات الحرارية المسجلة على دوائر العرض نفسها على المستوى العالمي وهذا ما يوضحه جدول(1). يُلحظ من الجدول أنَّ جميع دوائر العرض قد سجلت فرقاً بين المعدلين المسجلين على المستوى المحلي والعالمي، كان أكبر فرق بين المعدلين سجل في دائرة عرض(0ب) شمالاً إذ بلغ(0.0)مْ، فيما كان أقل فرق قد سجل في دائرة

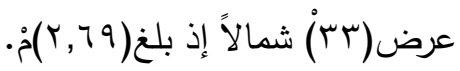


العـــــــد الثـلاثون

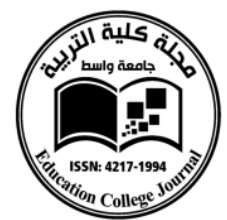

مجلـــة كليــــة التربيــــة

جدول(1)

الفرق بين المعدل العالمي والمعدل المحلي لدرجات الحرارة الاعتيادية في دوائر العرض(مُ)

\begin{tabular}{|c|c|c|c|}
\hline الفرق بين المعدلين & معدل درجة الحرارة & معدل درجة الحرارة & دائرة العرض \\
\hline r.v^ & $r \cdot . \wedge$ & $i V_{\cdot} \cdot r$ & دائرة العرض ب ش شمالاً \\
\hline $0 . .0$ & rr.v & 18.70 & دائرة العرض هب شمالاً \\
\hline$\varepsilon . \cdot r$ & $r$ r.r & IA.Y^ & دائرة العرض ؛ بشمالاً \\
\hline r.79 & r. & 11.91 & دائرة العرض بr شمالاً \\
\hline צ. & rr.q & $19.0 \leqslant$ & دائرة العرض r T شمالاً \\
\hline$\varepsilon . v r$ & $r \leq .9$ & $r . .1 v$ & دائرة العرض اس شمالاً \\
\hline$\varepsilon .7$ & ro.s & $r . . \Lambda$ & دائرة العرض · ب شمالاً \\
\hline
\end{tabular}

المصدر : عمل الباحث اعتماداً على: 1- الهيأة العامة للأنواء الجوية والرصد الزلزالي، بيانات غير منشورة.

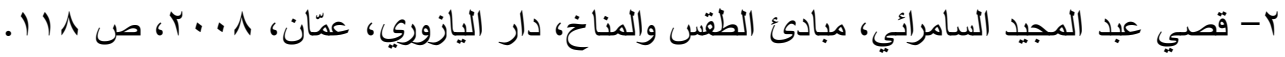

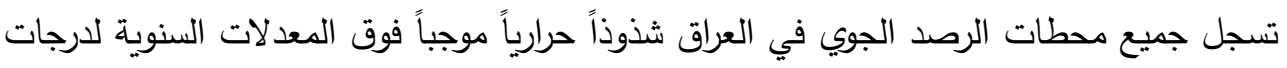

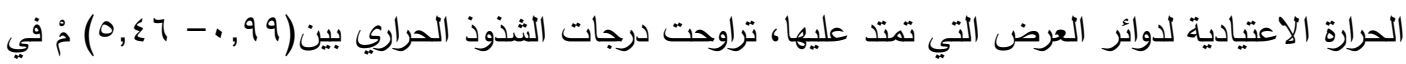

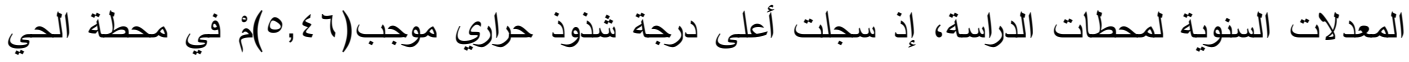

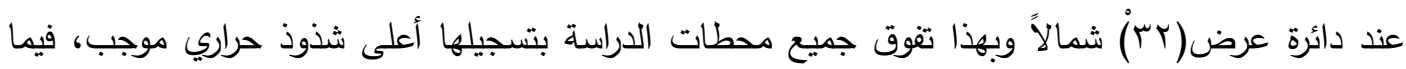

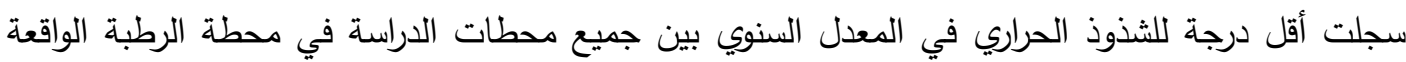

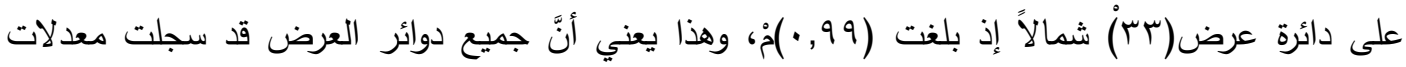

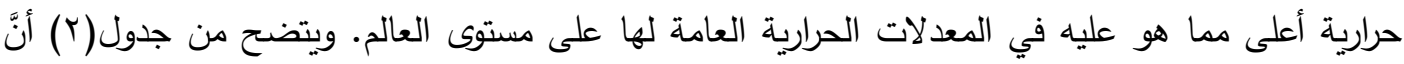

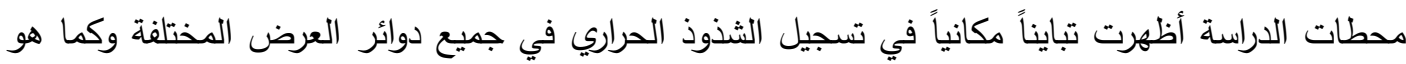
واضح من جدول(r) وخريطة (r) أدناه. 


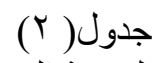

الثذوذ الحر اري في المعدلات السنوية لدرجة الحر ارة الاعتيادية (مْ) للمحطات المناخية

\begin{tabular}{|c|c|c|c|c|c|c|}
\hline المراري الثذوذ المستى & المراري الثذوذ المستىى & 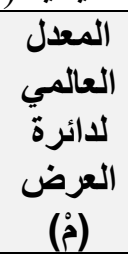 & العرض فعلئرة العرة & 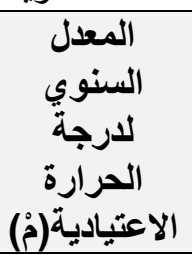 & شائرة العرضاً & المحطة \\
\hline$r .91$ &.$r$ & \multirow{3}{*}{$I V . r$} & \multirow{3}{*}{$r \cdot . \Lambda$} & YI & \multirow{3}{*}{ rq } & تلعفر \\
\hline$\varepsilon .1$ & $\cdot r$ & & & YI. & & سنجار \\
\hline r. Y & $\because 0^{\circ}$ & & & $r \cdot . r$ & & الموصل \\
\hline$\varepsilon .90$ & $.1=$ & \multirow{2}{*}{18.70} & \multirow{2}{*}{ Yr. V } & YY. & \multirow{2}{*}{ ro } & مخمور \\
\hline 0.10 & .1 & & & YY.A & & كركوك \\
\hline$\varepsilon . \varepsilon Y$ & $\cdot . \varepsilon$ & \multirow{3}{*}{$\Lambda \Lambda . Y \Lambda$} & \multirow{3}{*}{ YY.r } & YY.V & \multirow{3}{*}{$r \varepsilon$} & بيجي \\
\hline$\varepsilon .7 r$ &. .7 & & & r. Y.q & & خانقين \\
\hline$r . r$ & 1. & & & YI.r & & حديثة \\
\hline r.pq & $. r=$ & \multirow{4}{*}{11.91} & \multirow{4}{*}{1.7} & rI.r & \multirow{4}{*}{ r } & الخالص \\
\hline r.Yq &. .7 & & & YY.Y & & الرمادي \\
\hline 4.99 & $1 . r$ & & & Pr.q & & بغداد \\
\hline. .99 & $1 . V=$ & & & 19.9 & & الرطبة \\
\hline$\varepsilon .77$ & $\cdot r$ & \multirow{4}{*}{$19.0 \leqslant$} & \multirow{4}{*}{ rr.q } & $r \leqslant . r$ & \multirow{4}{*}{ rr } & كربلاء \\
\hline r.^ & .0 & & & rT.z & & الحلة \\
\hline 0.87 & 1.1 & & & ro & & الحي \\
\hline$r . \leqslant 7$ & $\because 9=$ & & & $r r$ & & النخيب \\
\hline$\varepsilon . \varepsilon r$ &.$r_{-}$ & \multirow{5}{*}{$r . .1 V$} & \multirow{5}{*}{$r \varepsilon . q$} & $r \varepsilon .7$ & \multirow{5}{*}{ r } & النجف \\
\hline$\varepsilon . Y T$ & $\because 0$ & & & $r \leqslant . \varepsilon$ & & الديوانية \\
\hline$\varepsilon . V \mu$ & - & & & $r \varepsilon . q$ & & العمارة \\
\hline$\varepsilon . \wedge \mu$ & . & & & $r \varepsilon . q$ & & السماوة \\
\hline ט.M &. .7 & & & ro. 0 & & الناصرية \\
\hline$\varepsilon .9$ &.$r$ & \multirow{2}{*}{$r \cdot . \Lambda$} & \multirow{2}{*}{ Yo. $\varepsilon$} & Yo. & \multirow{2}{*}{ r. } & الحسين \\
\hline$\varepsilon . \varepsilon$ & $. r=$ & & & $r 0 . r$ & & المطار \\
\hline
\end{tabular}




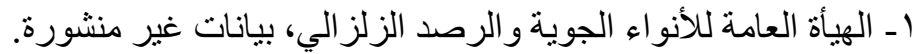

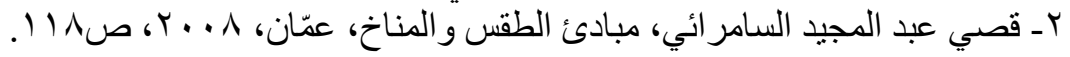

خربطة(Y)

الثذوذ الحراري في المعدلات السنوية لدرجة الحرارة الاعتيادية على المستوى العالمي حربي

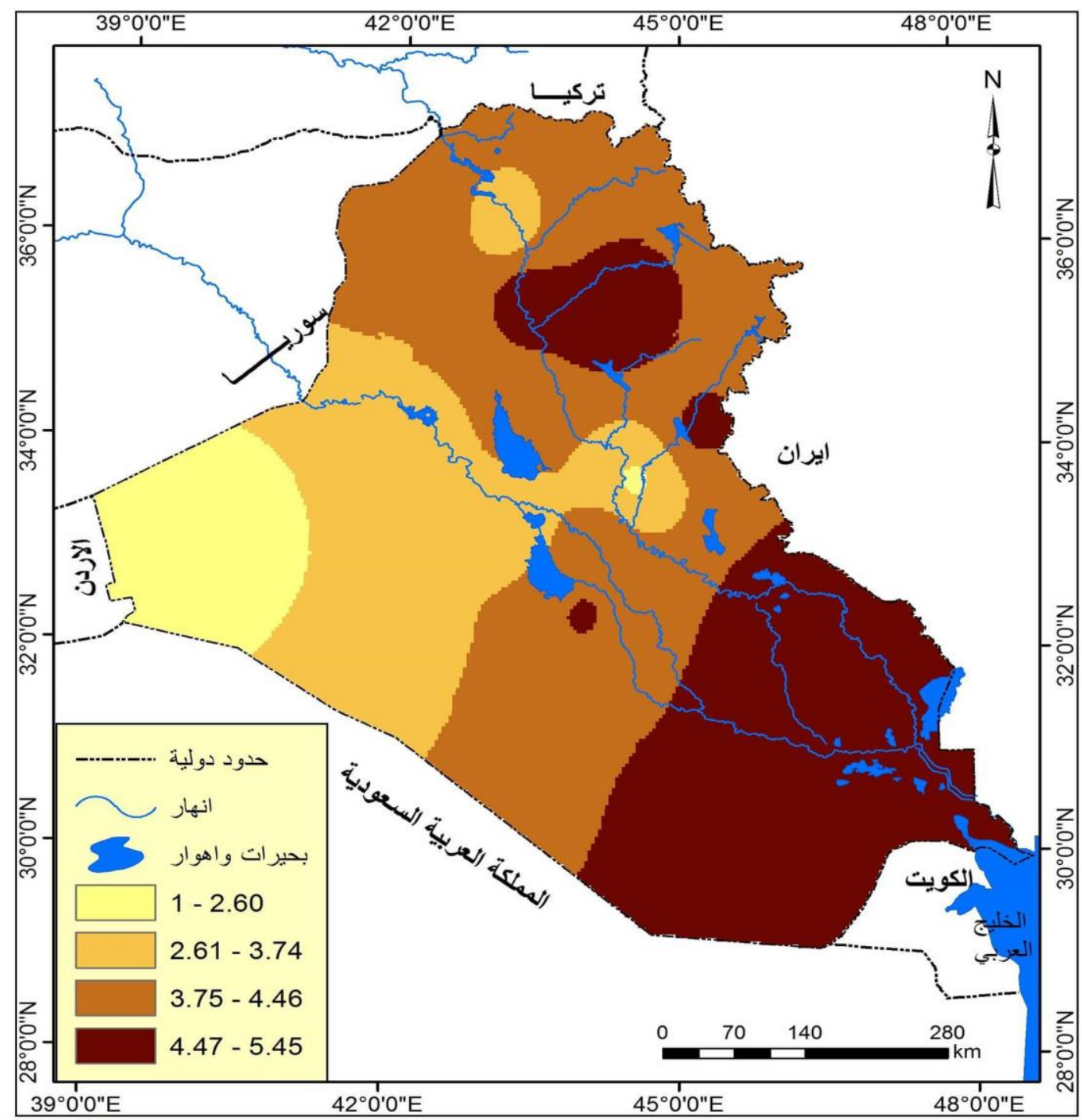

المصدر : عمل الباحث اعتماداً على:

ا- برنامج 10.3 


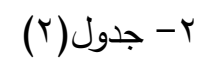

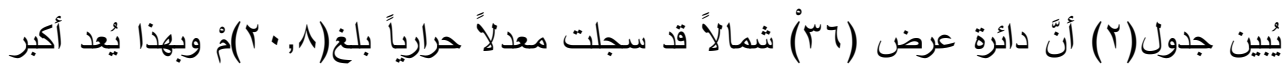

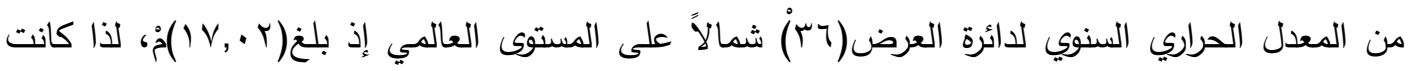

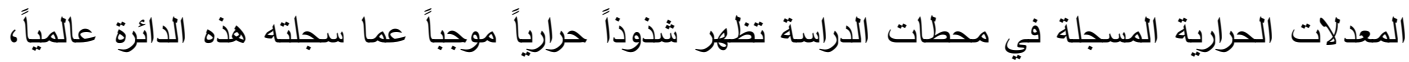

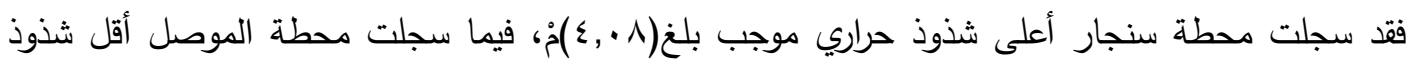

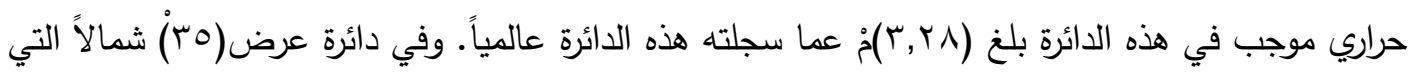

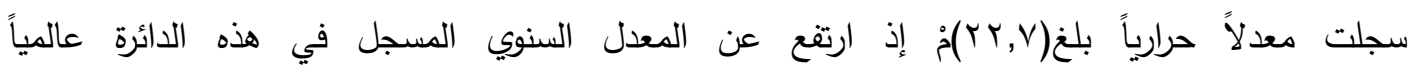

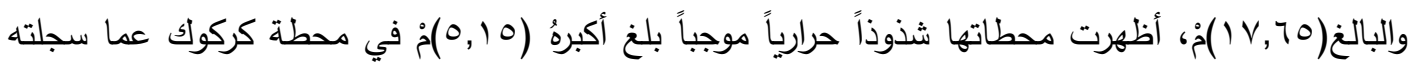

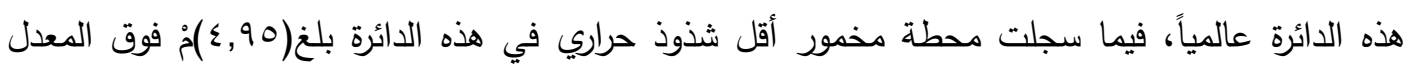

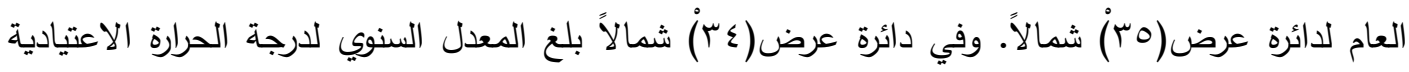

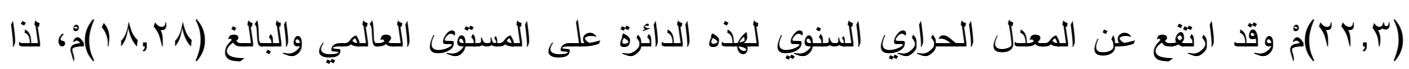

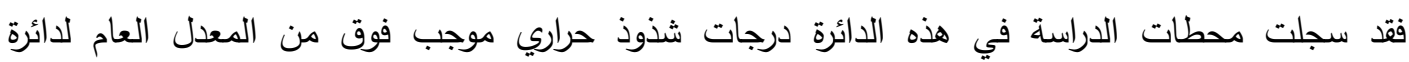

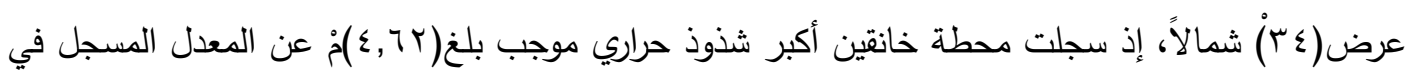

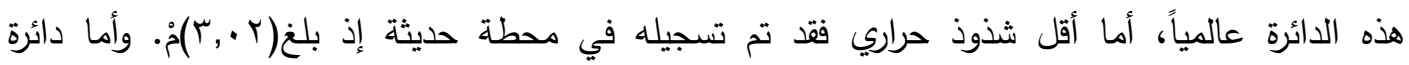

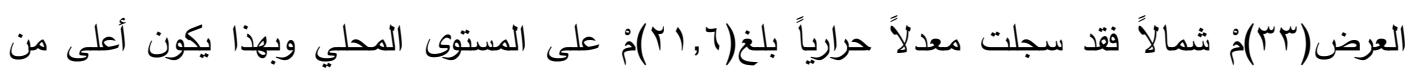

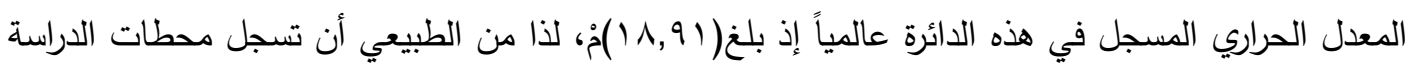

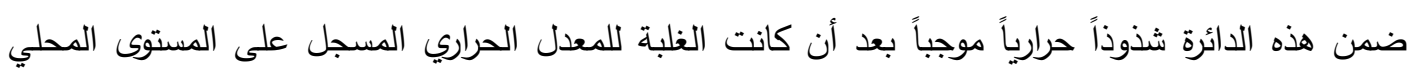

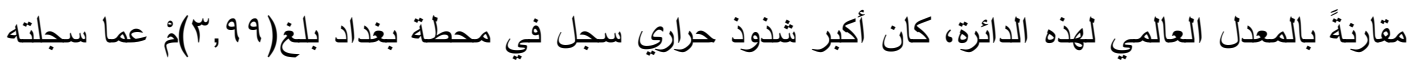

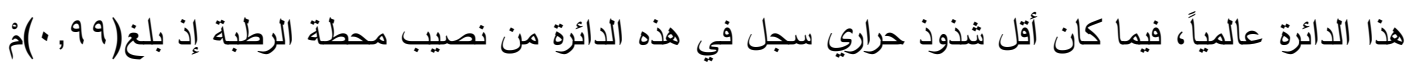

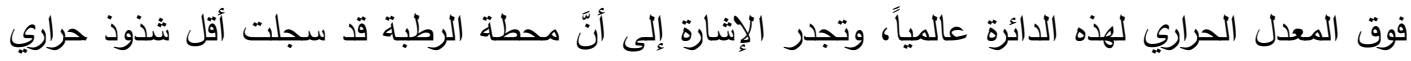

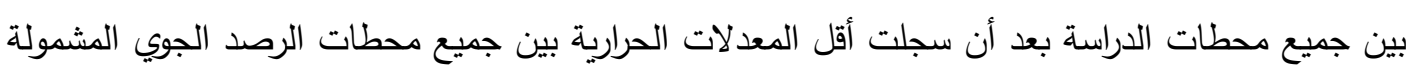

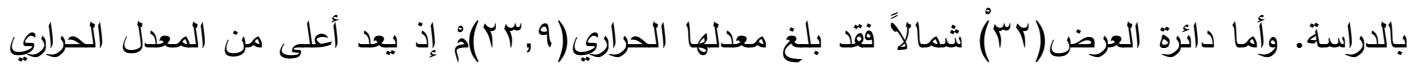

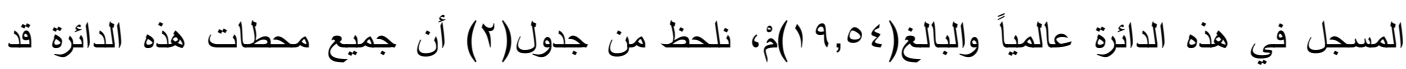

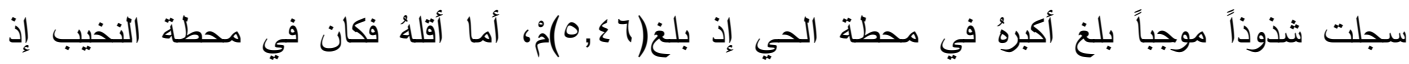

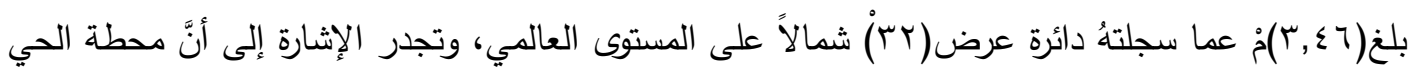

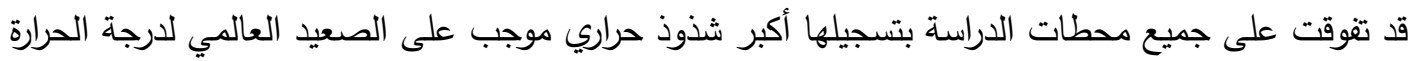

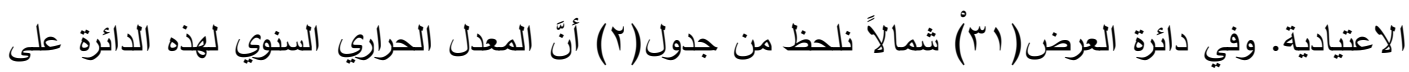




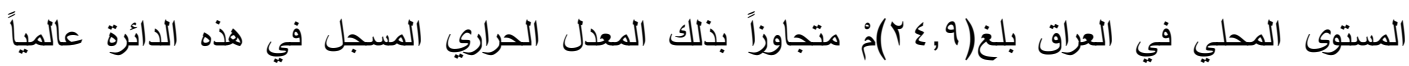

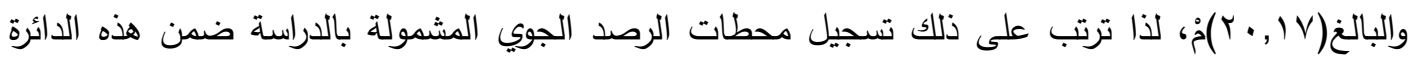

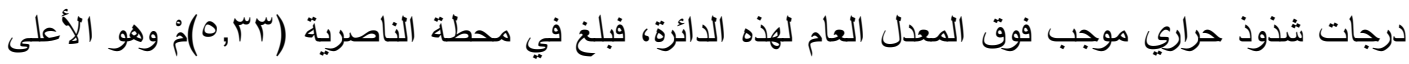

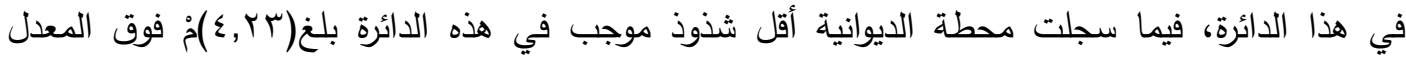

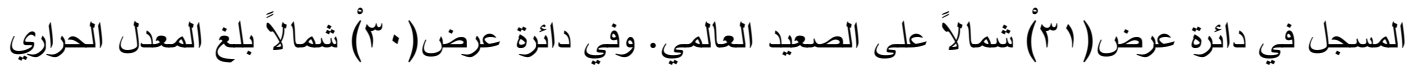

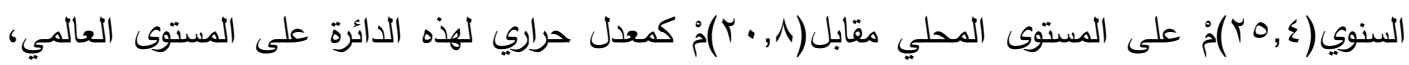

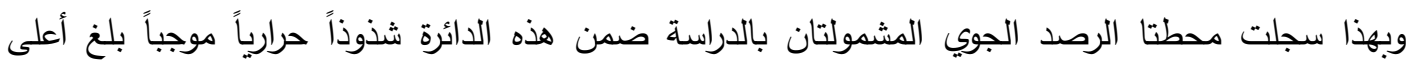

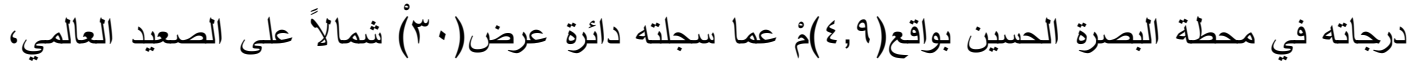

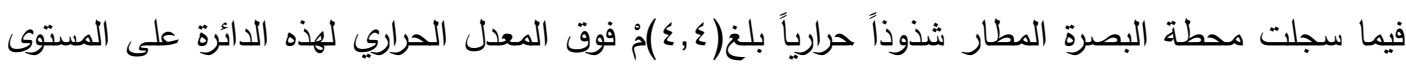
العالمي.

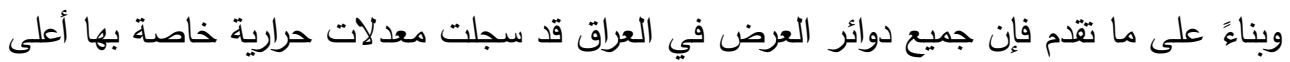

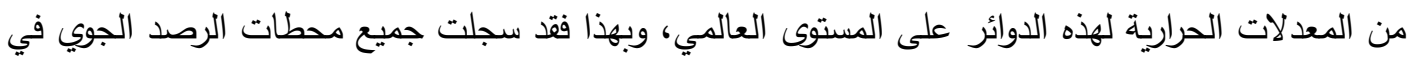

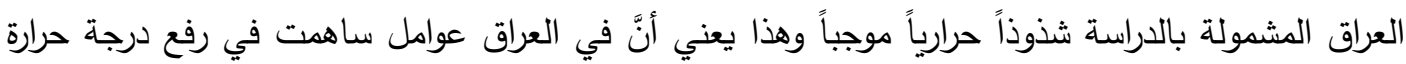

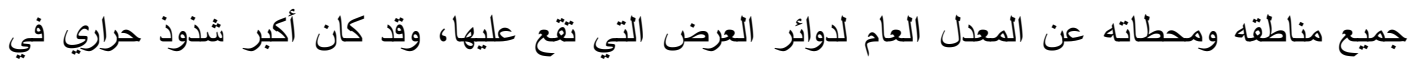

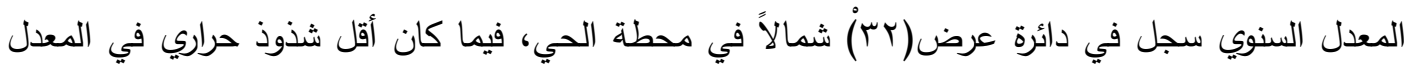

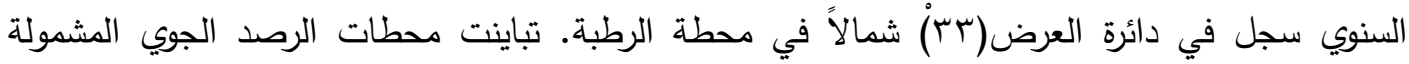

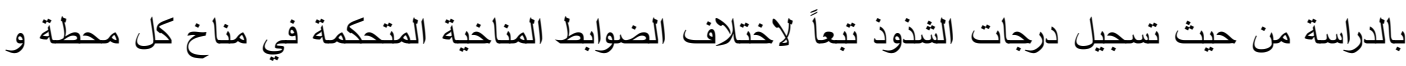

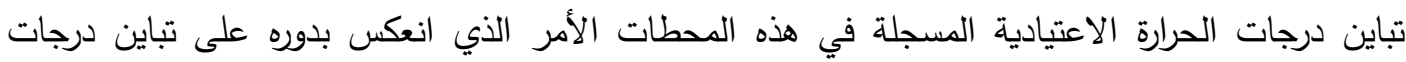
الثذوذ في هذه المحطات، ينظر جدول(r). 
العــــــد الثلاثون

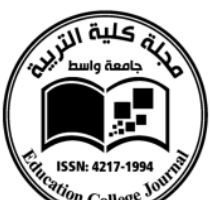

ation College

مجلـــة كليـــة التربيــة

جدول(r) (بن)

الترتيب التنازلي لمحطات الدر اسة من حيث الثذوذ الحراري عالمياً

\begin{tabular}{|c|c|c|c|}
\hline 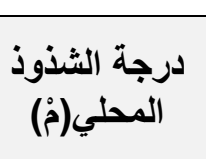 & دالعالمي(مُ) الثذوذ & اللارجة الحرارة السنية & المحطة \\
\hline 1.1 & 0.57 & ro & الحي \\
\hline .9 & $0 . \mu r$ & Yo.A & الناصرية \\
\hline .1 & 0.10 & YY.A & كركوك \\
\hline $.1-$ & $\varepsilon .90$ & PY.T & مخمور \\
\hline$\cdot r$ & 8.9 & ro.V & بصرة الحسين \\
\hline .1 & $\varepsilon . \wedge r$ & ro & السماوة \\
\hline . & $\varepsilon . V r$ & $r \varepsilon . q$ & العمارة \\
\hline.$r$ & $\varepsilon .79$ & $r \leqslant . r$ & كربلاء \\
\hline. .7 & $\varepsilon .74$ & Pr.q & خانقين \\
\hline$\cdot r=$ & $\varepsilon . \leqslant T$ & $r \leqslant .7$ & النجف \\
\hline$\cdot . \varepsilon$ & $\varepsilon . \varepsilon r$ & rY.V & بيجي \\
\hline$\cdot r_{-}$ & $\varepsilon . \varepsilon$ & $r O . r$ & بصرة المطار \\
\hline .0 & $\varepsilon . r \mu$ & $r \leqslant . \varepsilon$ & الايوانية \\
\hline$\cdot r$ & $\varepsilon .11$ & $r 1.1$ & سنجار \\
\hline $1 . r$ & $r .99$ & YY.q & بغداد \\
\hline.$r$ & $r .91$ & rI & تلعفر \\
\hline .0 & r.A & Tr.s & الطلة \\
\hline $.9-$ & $r . \leqslant 7$ & $r r$ & النخيب \\
\hline .7 & $r . r q$ & YY.Y & الرمادي \\
\hline .0 & r. rA & $r \cdot r$ & الموصل \\
\hline 1. & $r . \cdot r$ & $r . r$ & حديثة \\
\hline$. r=$ & r.rq & $r 1 . r$ & الخالص \\
\hline $1 . V=$ & $\because 99$ & 19.9 & الرطبة \\
\hline
\end{tabular}

المصدر : عمل الباحث اعتماداً على: ا- جدول(r) 

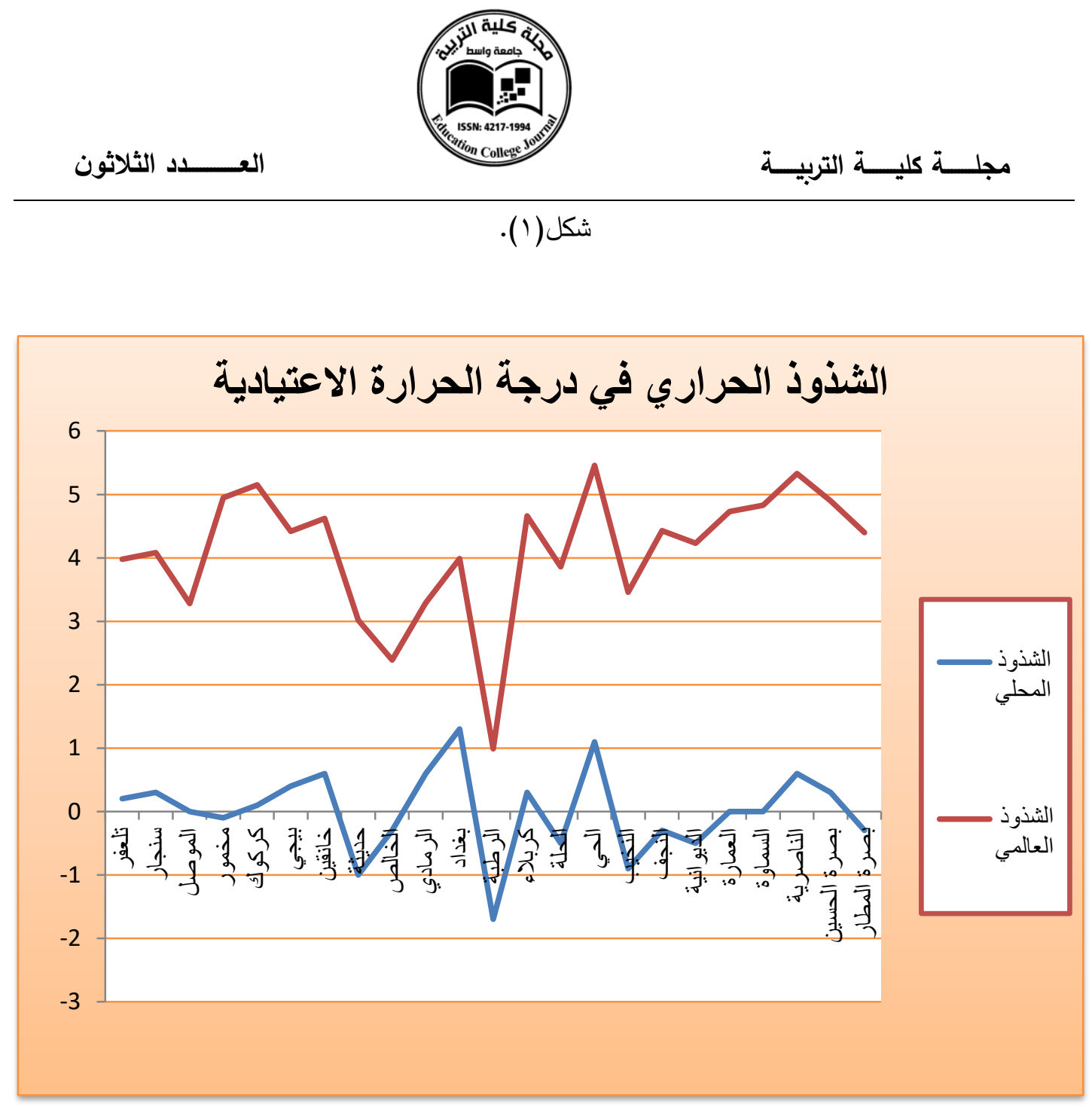

المصدر : عمل الباحث اعتماداً على:

ا-جدول(r) البان 
شكل(r)

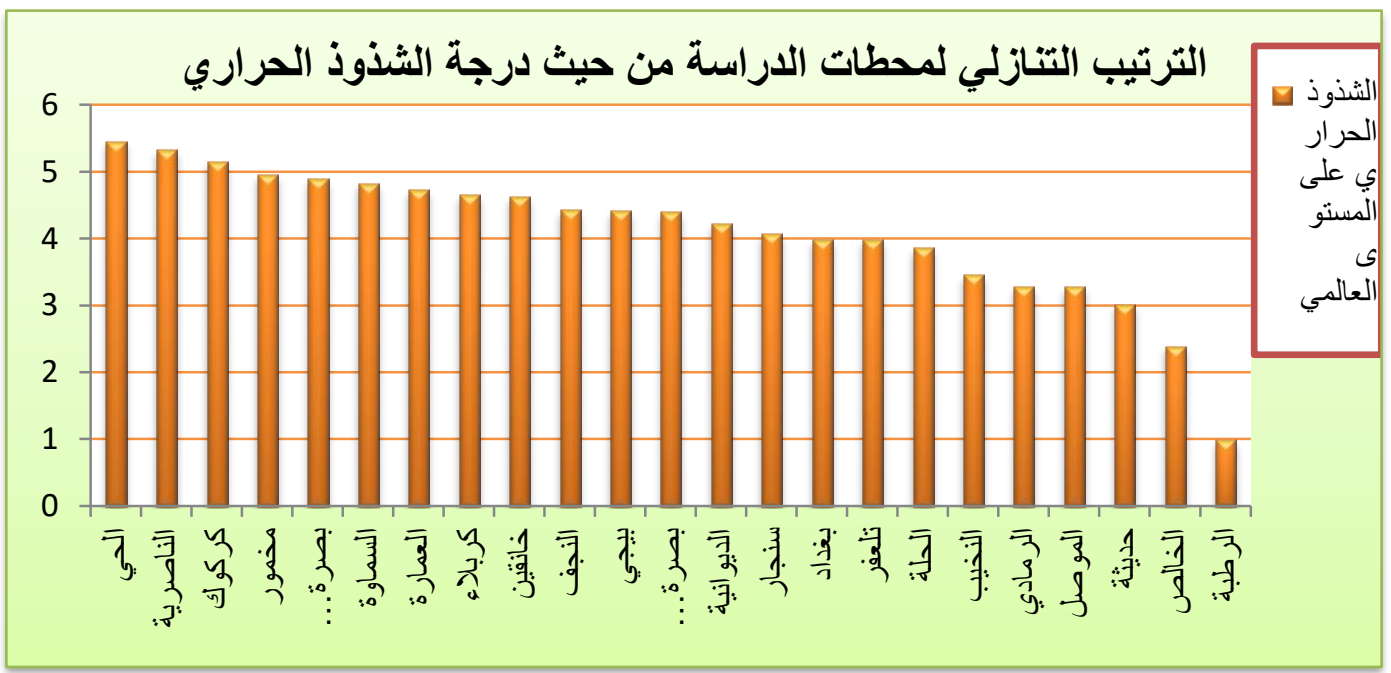

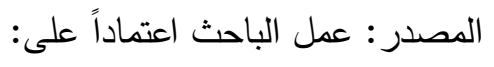

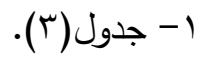

يُلحظ من جدول (r) وشكل(r) أنّ ترتيب المحطات لا يأخذ نسقاً مع ترتيبها حسب درجات العرض وهذا.

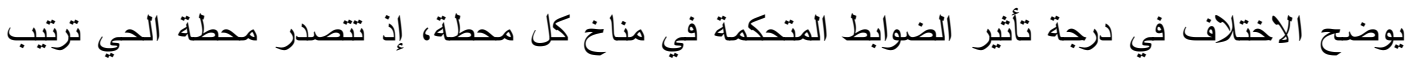

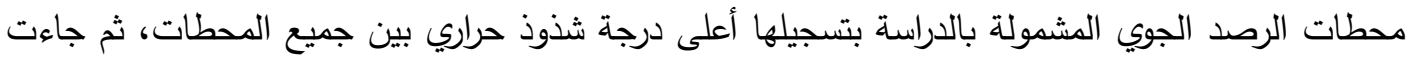

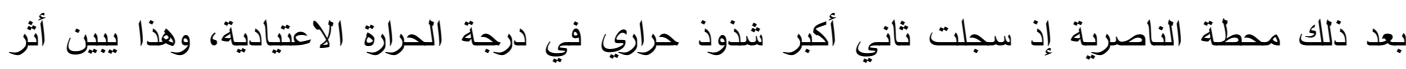

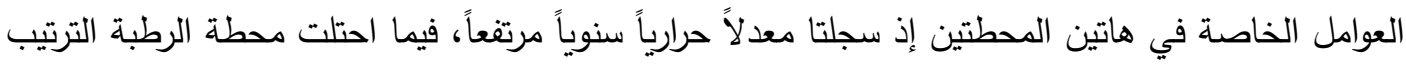

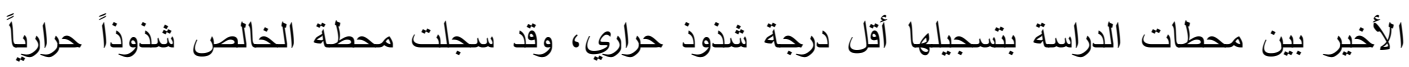

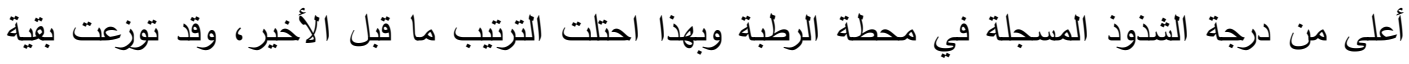
محطات الدراسة على سلم الترتيب الخاص بدرجات الثذوذ كلٌ حسب درجة الثذوذ الحراري المسجلة فيها

وكما هو واضح من جدول(r). 
وتجدر الإشارة إلى أنَّ جميع محطات الدراسة لها عوامل خاصة بها ساهمت في صياغة الثذذذ الحراري فيها بهذا الترتيب السابق وأن كانت بعض هذه العوامل قد اشتركت فيها معظم محطات الدراسة وهذا

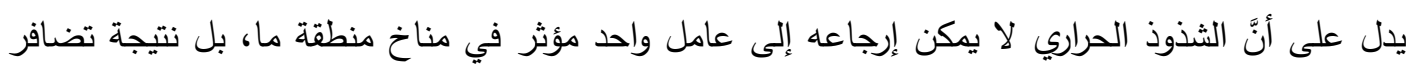

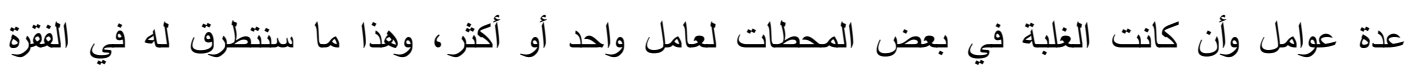
الخاصة بالضوابط المناخية المؤثرة في الثذوذ الحراري في العراق. ץ- التحليل المناخي للثذوذ الحراري في العرلق على المستوى المحلي:

تعكس المعدلات الحرارية السنوية والثهرية لدوائر العرض في العراق الحالة الحرارية التي تتصف

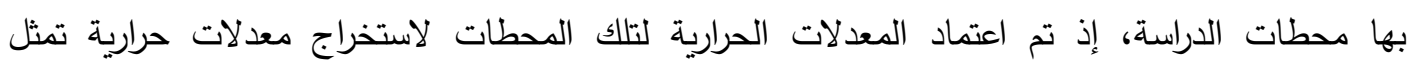
الخصائص المناخية لدوائر العرض في العراق ومن ثم استخراج درجة الثذوذ الحراري المسجلة في محطات الدراسة وهذا ما تضمنه جدول(ع) وخريطة لـائر). 
العـــــــد الثلاثون

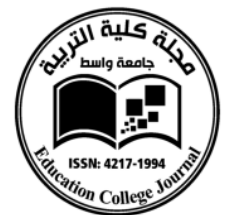

جدول(६)

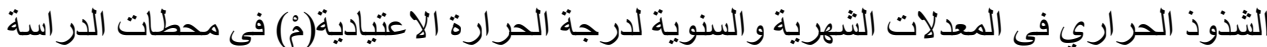

\begin{tabular}{|c|c|c|c|c|c|c|c|c|c|c|c|c|c|c|}
\hline $\begin{array}{l}\overline{3} \\
3 \\
\overline{3} \\
\overline{3} \\
\text { y. }\end{array}$ & $\begin{array}{l}\frac{y}{3} \\
.3 \\
\overline{3}\end{array}$ & $\begin{array}{l}3 \\
3 \\
3 \\
3 \\
3 \\
3\end{array}$ & $\begin{array}{l}3 \\
3 \\
3 \\
3 \\
3\end{array}$ & 栗 & '丁. & 尘 & $\frac{3}{3}$ & 3 & 霍 & : & ב3. & $\begin{array}{l}\sqrt[y]{3} \\
.3 \\
\sqrt[3]{3}\end{array}$ & $\begin{array}{l}\frac{7}{3} \\
\frac{0}{3} \\
\overline{3} \\
.3\end{array}$ & المحطة \\
\hline$\cdot r$ & $1 . \varepsilon$ & $\begin{array}{l}- \\
.1\end{array}$ & $\cdot .7$ & $\because 0$ & $\because r$ & $\cdot r$ & $\begin{array}{l}- \\
\ddots 1\end{array}$ & $\cdot r$ & $\cdot r$ & $\begin{array}{l}- \\
.1\end{array}$ & $\begin{array}{r} \\
\end{array}$ & $\cdot r$ & \multirow{3}{*}{$r^{4}$} & تلعفر \\
\hline$\cdot r$ & $\bar{r}$ & $\because .9$ & $\cdot v$ & $\because 0$ & $\cdot r$ & $\cdot r$ & $\because r$ & $\cdot r$ & $\cdot r$ & .1 & $\because 1$ & .1 & & سنجار \\
\hline 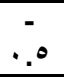 & $\overline{1 . r}$ & $\cdot \vec{v}$ & $\overline{1}$ & 1. & $\begin{array}{l}- \\
\end{array}$ & $\begin{array}{l}- \\
\therefore .\end{array}$ & $\begin{array}{l}- \\
.1\end{array}$ & $\begin{array}{l} \\
\end{array}$ & $\bar{\theta}$ & . & $\because 1$ & $\bar{r}$ & & الموصل \\
\hline 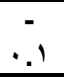 & $\cdot \dot{r}$ & $\begin{array}{l}- \\
.1\end{array}$ & . & $\begin{array}{l}- \\
.1\end{array}$ & $\begin{array}{l}-r \\
\dot{r}\end{array}$ & . & $\begin{array}{l}- \\
\therefore r\end{array}$ & . & 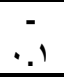 & $\begin{array}{l}- \\
\dot{ }\end{array}$ & $\begin{array}{r}- \\
\dot{r}\end{array}$ & $\begin{array}{l}- \\
.1\end{array}$ & \multirow[t]{2}{*}{ ro } & مخمور \\
\hline$\because 1$ & $\cdot r$ & $\because 1$ & . & $\because 1$ & $\theta r$ & . & $\cdot . r$ & . & .1 & $\cdot r$ & $\cdot r$ & .1 & & كركوك \\
\hline$\because \varepsilon$ & $\because 1$ & $\because 1$ & $\because 1$ & $\because \varepsilon$ & $\because 0$ &.$\wedge$ & 1 & $\because r$ & .9 & $\because r$ & $\theta r$ & $\cdot r$ & \multirow{3}{*}{ } & بيجي \\
\hline$\cdot .7$ & 1 & $\because 9$ & $\cdot .9$ & $\cdot . \varepsilon$ & $\cdot . \varepsilon$ & $\cdot \wedge$ & 1.1 & $\because v$ & $\cdot r$ & $\cdot r$ & $\cdot \varepsilon$ & $\because v$ & & خانقين \\
\hline 1. & $\overline{1.1}$ & 1. & $1=$ & $\begin{array}{l}-1 \\
\therefore \wedge\end{array}$ & $\begin{array}{c}- \\
\therefore 9\end{array}$ & $\overline{1 . V}$ & $\begin{array}{r}- \\
.1\end{array}$ & $\begin{array}{l}- \\
\therefore 9\end{array}$ & $\cdot \bar{A}$ & $\therefore$ & $\cdot \vec{v}$ & $1-$ & & حيثة \\
\hline$\cdot \vec{r}$ & -1 & $\overline{-}$ & $\cdot r$ & $\begin{array}{l}- \\
\cdot \wedge\end{array}$ & $\begin{array}{l}- \\
\therefore \wedge\end{array}$ & $\begin{array}{r}- \\
\therefore . V\end{array}$ & $\begin{array}{l}- \\
\therefore 0\end{array}$ & - & $\cdot r$ & $\begin{array}{r}- \\
\ddots .7\end{array}$ & $\begin{array}{l}- \\
\therefore . \varepsilon\end{array}$ & $\because 0$ & \multirow{4}{*}{$r r$} & الخالص \\
\hline$\because v$ & $\because \wedge$ & .7 & $\because 0$ & $\because 0$ & .9 & 1 & .9 & $\because \wedge$ & $\therefore 0$ & $\because V$ & $\because 0$ & $\therefore \varepsilon$ & & الرمادي \\
\hline $1 . r$ & $\because 0$ & $\because 9$ & $\cdot . \wedge$ & 1.0 & $1 . v$ & $1 . v$ & $1 . v$ & 1.9 & $1 . r$ & 1.0 & $1 . r$ & $\because 0$ & & بغذاد \\
\hline 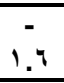 & $\overline{1 . r}$ & $\overline{1}$ & $\begin{array}{l}- \\
1.7\end{array}$ & $\begin{array}{l}- \\
1 . r\end{array}$ & $\begin{array}{l}- \\
1.7\end{array}$ & $r_{-}$ & $\begin{array}{r}- \\
\text { r. }\end{array}$ & $\begin{array}{r} \\
\\
\end{array}$ & $\begin{array}{r}- \\
r .1\end{array}$ & $\begin{array}{l}- \\
1.7\end{array}$ & $\overline{1 . r}$ & $\begin{array}{l}- \\
1 . \varepsilon\end{array}$ & & الرطبة \\
\hline$\cdot r$ & . & . & $\cdot r$ & $\because 0$ & $\cdot r$ & .9 &.$\varepsilon$ & \& & $\because r$ & $\cdot r$ & $\cdot r$ & $\cdot r$ & \multirow{4}{*}{ rr } & كربلاء \\
\hline$\therefore$ & -1 & $\cdot \vec{v}$ & $\bar{\theta}$ & 1.1 & $\overline{1}$ & 1.1 & $\begin{array}{c}- \\
\therefore 9\end{array}$ & $\bar{r}$ & $\cdot \dot{r}$ & -1 & $\because 1$ & . & & الطلة \\
\hline 1.1 & 1 & 1.4 & 1.7 & 1.1 & $\cdot 9$ & 1 & $1 . r$ & 1.8 & $\because V$ & $\because .9$ & 1 & 1.1 & & الحي \\
\hline $\begin{array}{l}- \\
.9\end{array}$ & $1-$ & $\begin{array}{l}- \\
\ddots V\end{array}$ & $\begin{array}{l}- \\
1.0\end{array}$ & $\begin{array}{c}- \\
.9\end{array}$ & $\begin{array}{l}- \\
\therefore 1\end{array}$ & $\begin{array}{l}- \\
\therefore 0\end{array}$ & $\begin{array}{c}- \\
\ddots \wedge\end{array}$ & $\overline{1 .}$ & $\begin{array}{c} \\
.7\end{array}$ & $\begin{array}{l}- \\
\ddots 9\end{array}$ & $\bar{i}$ & $\begin{array}{l}- \\
1 . r\end{array}$ & & النخيب \\
\hline $\begin{array}{r}r \\
\end{array}$ & $\begin{array}{l}- \\
\cdot V\end{array}$ & $\begin{array}{c} \\
.9\end{array}$ & $\ddots \varepsilon$ & $\begin{array}{l} \\
\cdot r\end{array}$ & $\theta r$ & $\because \varepsilon$ & $\begin{array}{l}- \\
\therefore 1\end{array}$ & $\begin{array}{c} \\
\end{array}$ & $\begin{array}{l}- \\
\therefore 0\end{array}$ & $\begin{array}{l}- \\
1.8\end{array}$ & $\begin{array}{l} \\
\end{array}$ & $\begin{array}{c} \\
.9\end{array}$ & \multirow{3}{*}{ r } & النجف \\
\hline $\begin{array}{l}- \\
.0\end{array}$ & -1 & $\begin{array}{l} \\
\cdot r\end{array}$ & $\begin{array}{c} \\
\cdot V\end{array}$ & $\begin{array}{c} \\
-.7\end{array}$ & $\begin{array}{c}- \\
.9\end{array}$ & $\begin{array}{r}- \\
\therefore .9\end{array}$ & $\begin{array}{c}- \\
.9\end{array}$ & $\begin{array}{r} \\
\end{array}$ & $\begin{array}{l} \\
\dot{r}\end{array}$ & $1=$ & $\begin{array}{r}- \\
\therefore 1\end{array}$ & $\begin{array}{l}- \\
\therefore 1\end{array}$ & & الديوانية \\
\hline . & . & $\because 1$ & $\because 1$ & $\theta r$ & $\because 1$ & $\because \varepsilon$ & $\because 0$ & 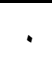 & $\begin{array}{l}-1 \\
\therefore 1\end{array}$ & $\overline{1}$ & $\begin{array}{l}\bar{\theta} \\
\dot{\theta}\end{array}$ & $\begin{array}{l}- \\
\therefore 1\end{array}$ & & العمارة \\
\hline
\end{tabular}

المصدر : عمل الباحث اعتماداً على : ا ـ الهيأة العامة للأنواء الجوية و الرصاء عد الزلز الي، بيانات غير منشورة. 


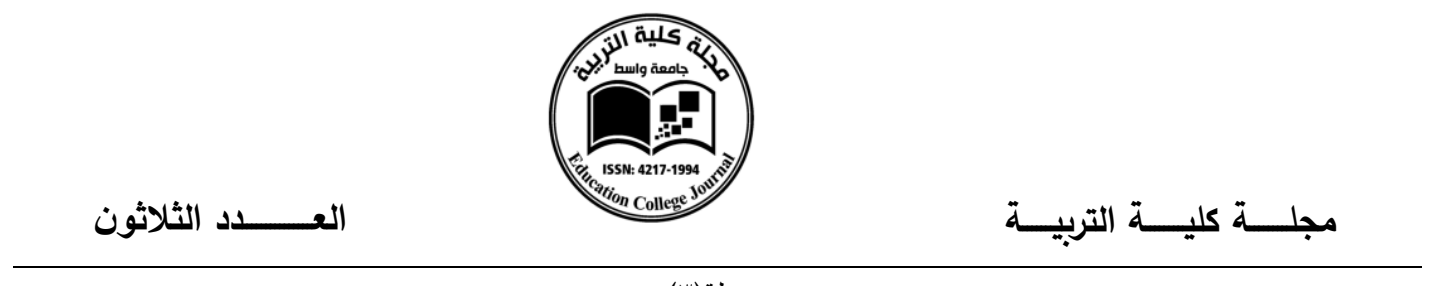

خريطة (ז)

الثذوذ الحراري في المعدل السنوي لدرجات الحرارة الاعتيادية على المستوى المحلي

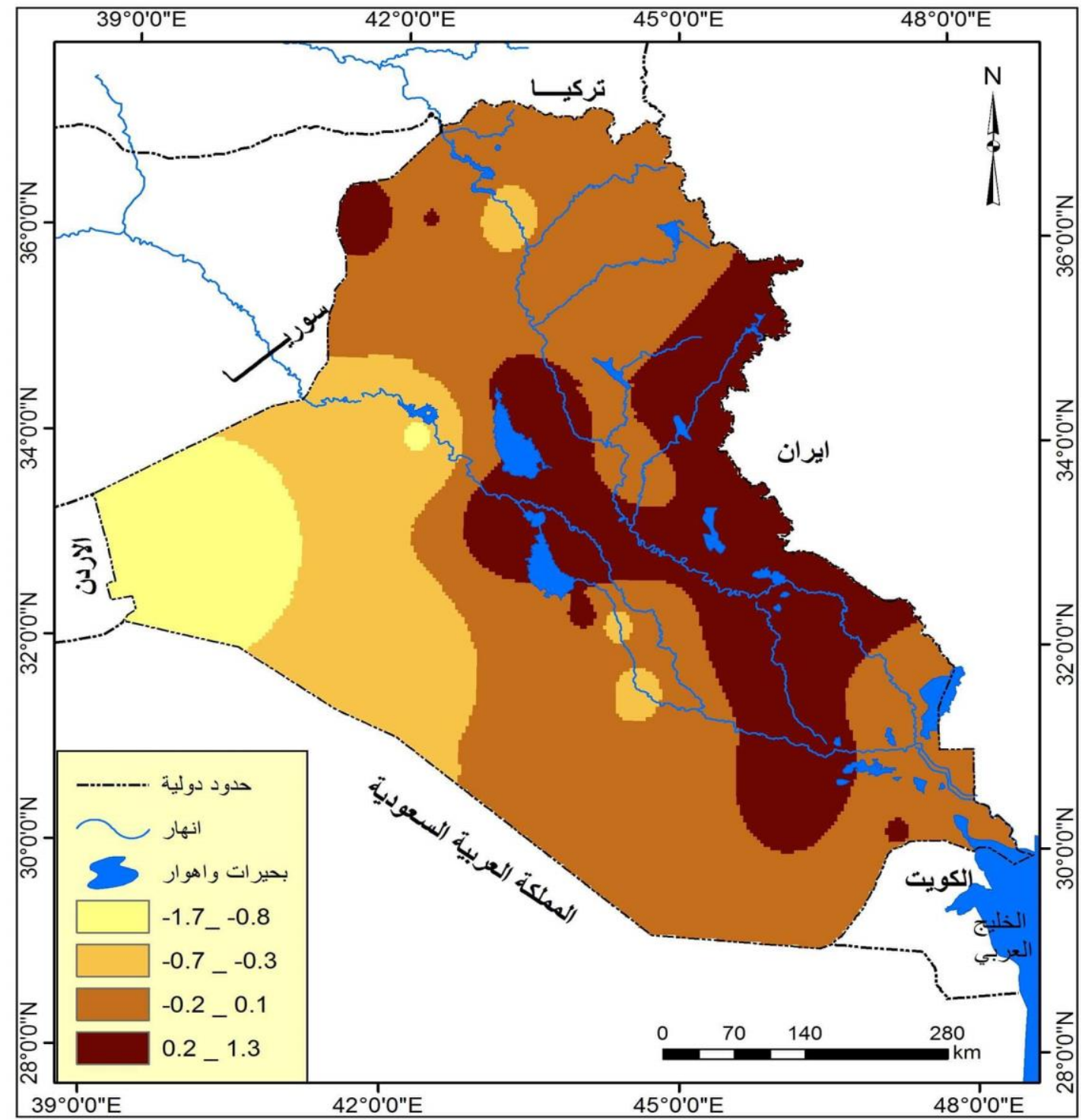

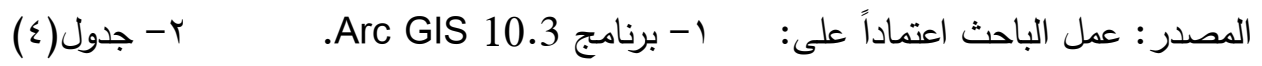


ץ-1- التباين المكاني للثذوذ العراري في المعدلات السنوية:

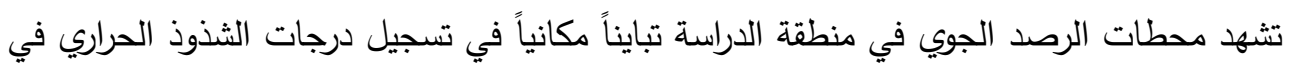

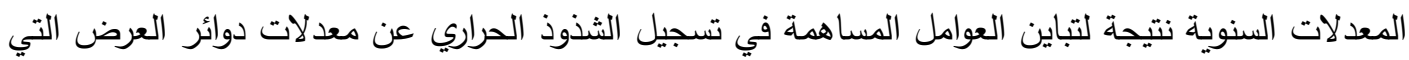

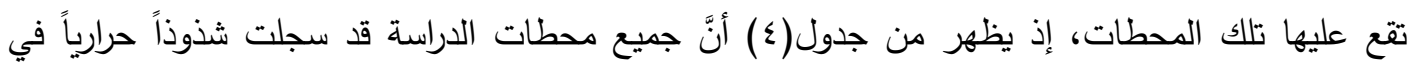

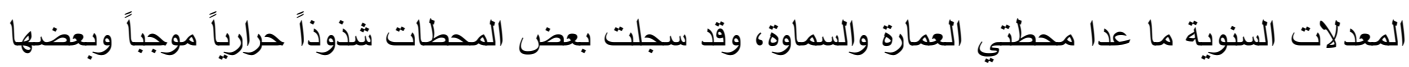

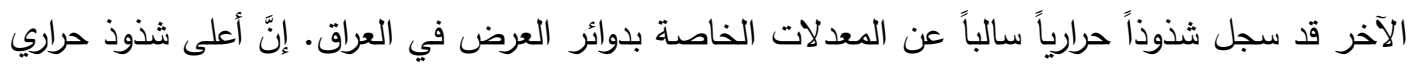
موجب على مستوى المعدل السنوي كان في محطة بغداد إذ بلغ(r, إ)جُ فوق المعدل الحراري السنوي لدائرة

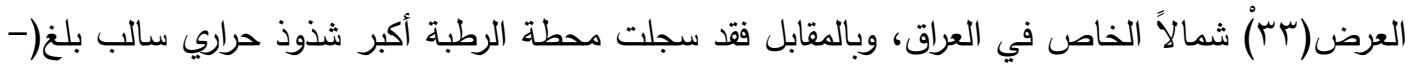

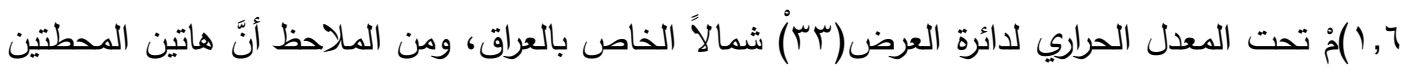

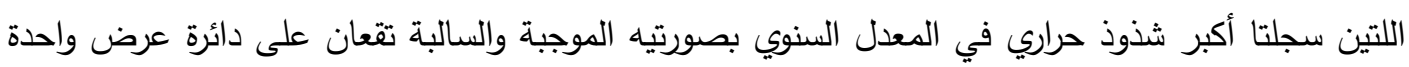

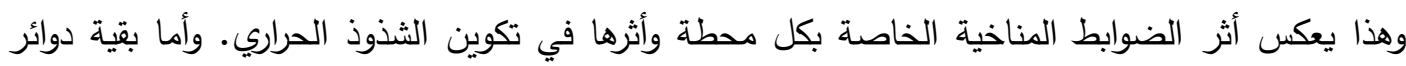

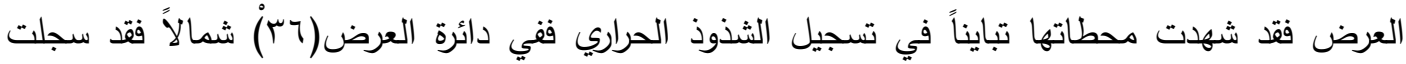

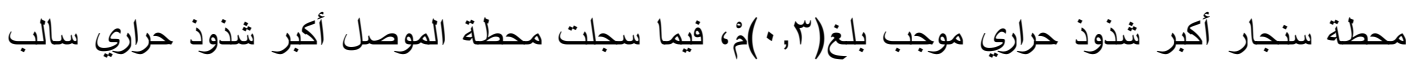

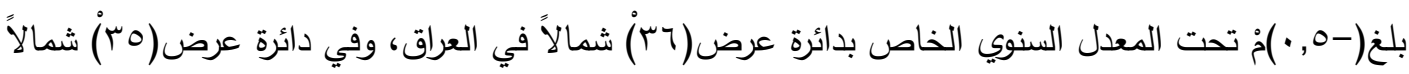

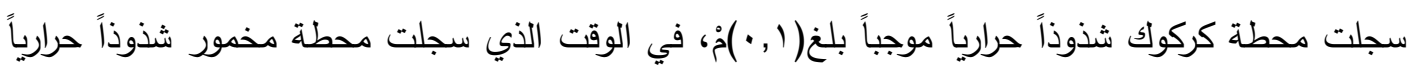

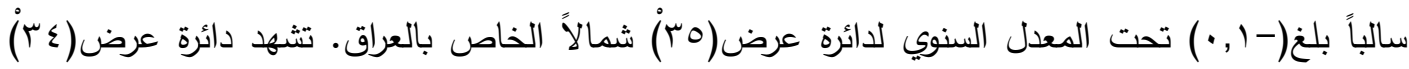

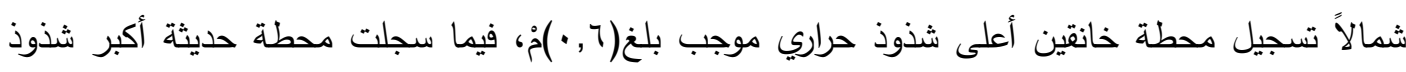

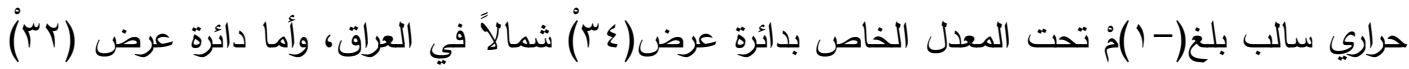

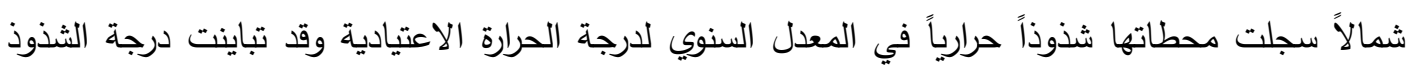

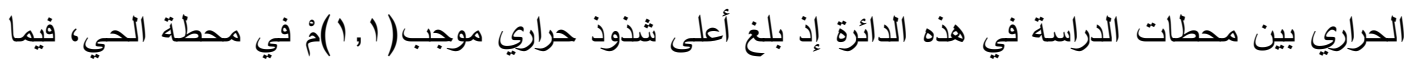

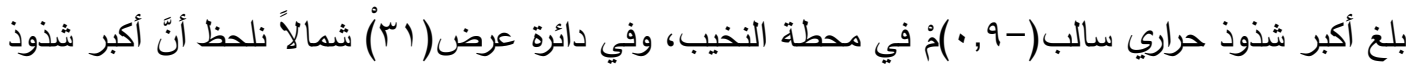

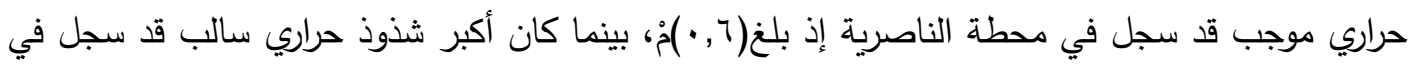

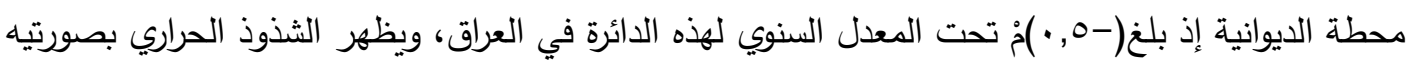

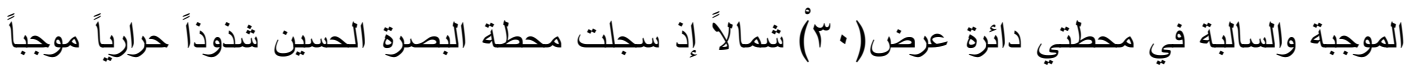

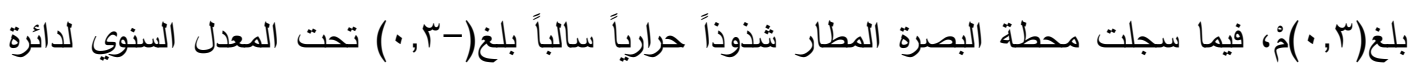
عرض(·r (r) شمالاً في العراق. 
العـــــــد الثلاثون

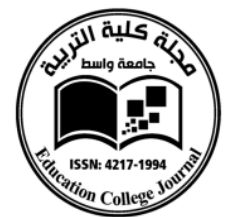

ولم يقتصر التباين المكاني للشذوذ الحراري على المعدلات السنوية وإنما أمتنَّ هذا التباين ليطال المعدلات الثهرية، إذ لم تتشابه المعدلات الحرارية الثهرية لمحطات الدراسة مع المعدلات الثهرية لدوائر العرض التي تقع عليها. وقد سُجِل الشذذذ الحراري في جميع محطات الدراسة و بكلا نوعيه الموجب والسالب. وكما يظهر من جدول(ع) أنَّ أكبر شذوذ حراري موجب في المعدلات الشهرية بلغ(9, ()جْ المسجل في محطة بغداد، فيما كان أكبر شذوذ حراري سالب ضمن المعدلات الشهرية قد بلغ(-Y,Y) والمسجل في محطة الرطبة، وعلى المستوى المكاني فقد شهدت دوائر العرض تبايناً في المعدلات الثهرية انعكس على تسجيل محطات الدراسة

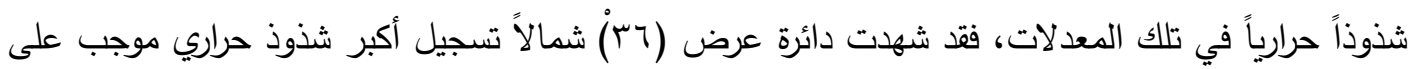
صعيد المعدلات الثهرية بلغ(ع,())ْ في محطة تلعفر، فيما كان أكبر شذوذ حراري سالب في المعدلات الشهرية قد بلغ(-r, () مُ، وفي دائرة عرض(0بْ) شمالاً سجلت محطاتها تبايناً في تسجيل الشذوذ الحراري في المعدلات الثهرية إذ سجلت محطة كركوك أكبر شذوذ حراري موجب في المعدلات الشهرية بلغ(س, •)مْ، وفي المقابل سجلت محطة مخمور أكبر شذوذ سالب في المعدلات الثهرية بلغ(-r,·) ڤ. وأما دائرة عرض(ع ب) شمالًا فقد شهدت محطاتها تبايناً في تسجيل الشذوذ الحراري إذ سجلت محطة خانقين أكبر شذوذ حراري موجب في المعدلات الثهرية بين محطات هذه الدائرة بلغ (1, (1)مُ، وأما محطة حديثة فقد سجلت أكبر

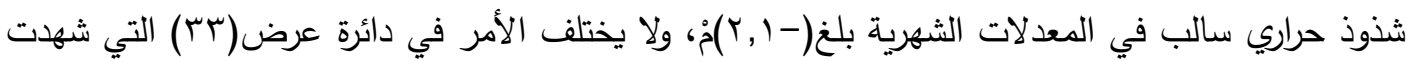
محطاتها تبايناً مكانياً في تسجيل الثذوذ الحراري في المعدلات الثهرية، فنجد أنَّ محطة بغداد قد سجلت أكبر شذوذ حراري موجب في المعدلات الثهرية بلغ(9, (1)؛ُ، وتعد أعلى درجة شذوذ حراري موجب مسجلة بين جميع المحطات على مستوى المعدلات الشهرية، فيما سجلت محطة الرطبة أكبر شذوذ حراري سالب بلغ(r,r)مُ وتعد أكبر درجة شذوذ حراري سالب مسجلة بين جميع المحطات وعلى مستوى المعدلات الثهرية. وفي دائرة عرض(rr) شمالاً نجد أنَّ محطة الحي قد تميزت بتسجيلها أكبر درجة شذوذ حراري موجب في المعدلات الثهري بلغت(7, (1)ْ، وأما محطة النخيب فقد سجلت أكبر شذوذ حراري سالب بلغ(م, 1) مُ. وأما دائرة عرض(اب) شمالاً فنلحظ أنَّ محطاتها قد شهدت تبايناً في تسجيل الثذوذ الحراري في المعدلات الثهرية إذ سجلت محطاتها درجات متباينة من الثذوذ الحراري وبكلا نوعيه الموجب والسالب، وقد سجلت محطة الناصرية أكبر شذوذ حراري موجب بلغ( ()مْ، فيما سجلت محطتا العمارة والنجف أكبر شذوذ

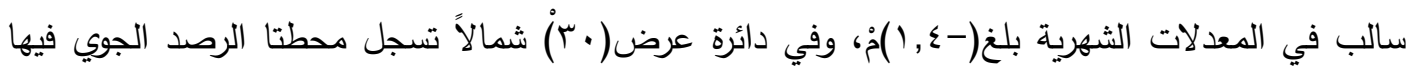
تبايناً في تسجيل الثذوذ الحراري في المعدلات الثهرية إذ سجلت محطة البصرة الحسين أكبر شذوذ حراري موجب بلغ (7, •)خْ، فيما سجلت محطة البصرة المطار أكبر شذوذ حراري سالب بلغ(-7, • )جْ. 
يُيين جدول(؟) حال جميع المحطات المناخية المشمولة بالدراسة التي سجلت شذوذاً حرارياً على مستوى المعدلات الهات

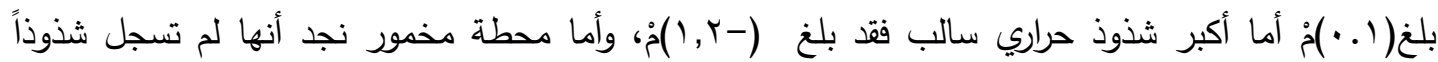
حرارياً موجباً في أي من المعدلات الثهرية، في حين سجلت أكبر شذوذ سالب بلغ (-r, •)مُ، وأما محطة كركوك فقد سجلت أعلى شذوذ حراري موجب بلغ(r, ·)مُ، في حين لم تسجل المحطة شذوذاً حرارياً سالباً في

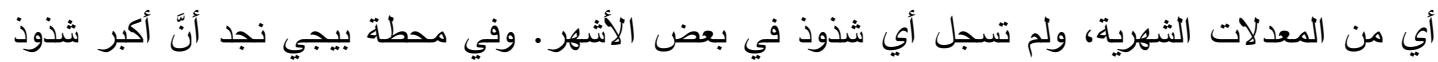

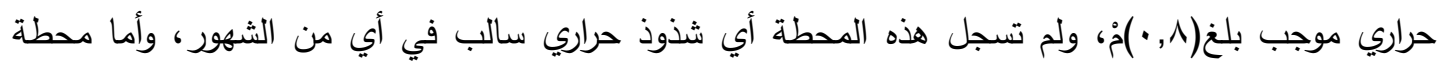

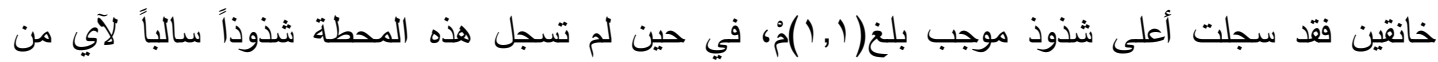

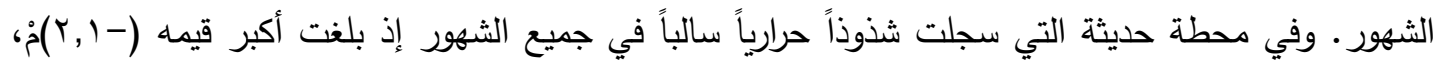

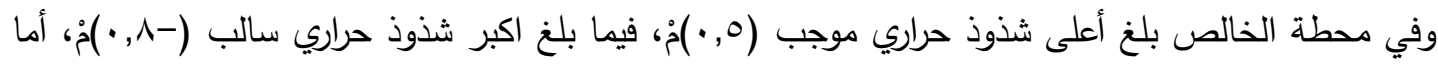

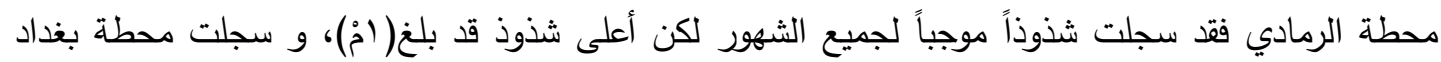
أكبر شذوذ حراري موجب بلغ(9, (1)جٌ ولم تسجل المحطة أي شذوذ حراري سالب في أي من الثهور، وكانت

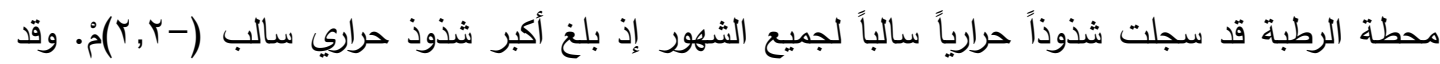

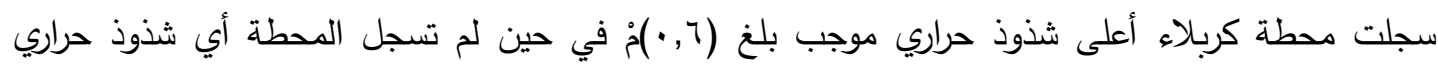

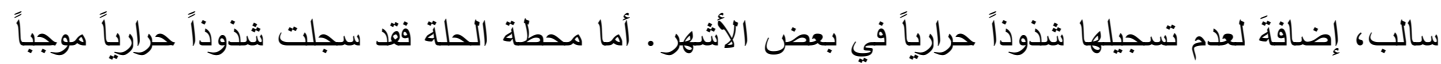

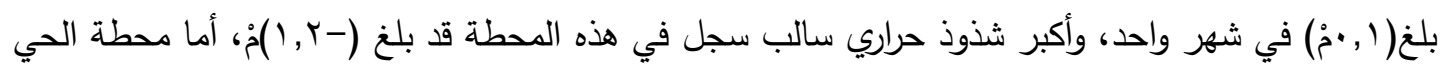

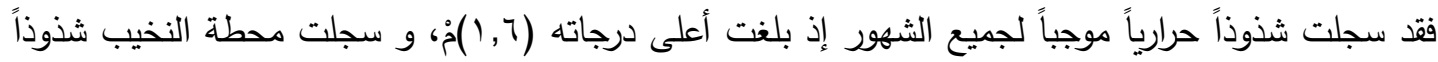

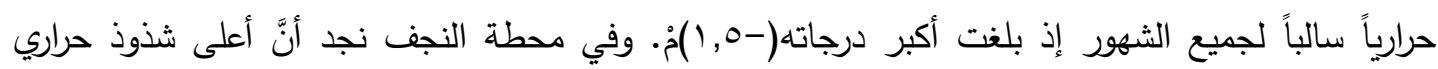

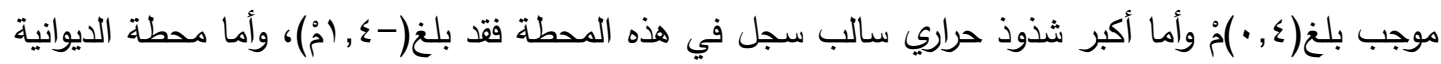

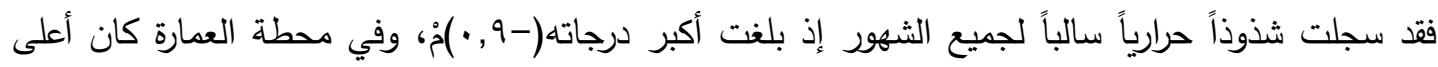

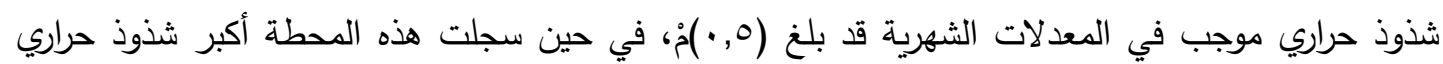

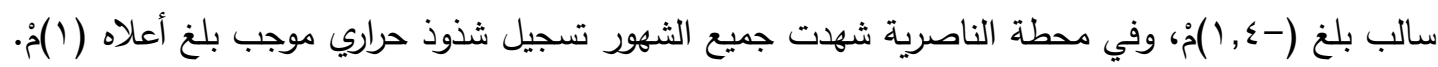

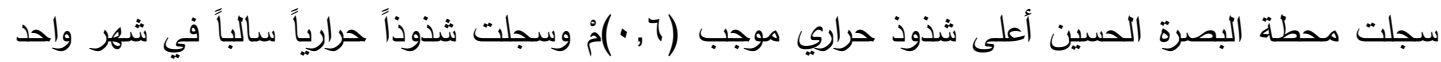

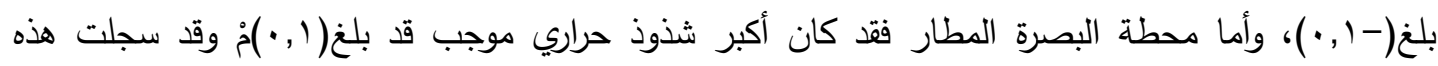

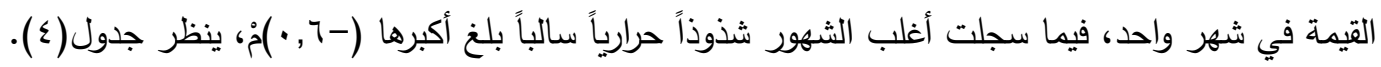


r-r - التباين الثهري للثذوذ الحراري في درجة الحرارة الاعتيادية:

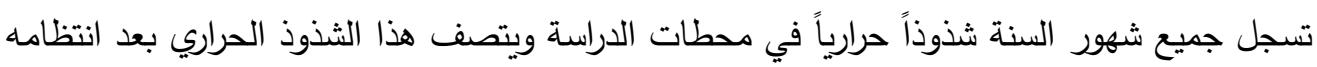

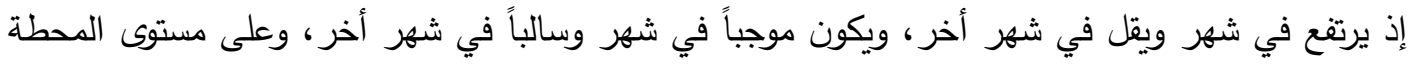

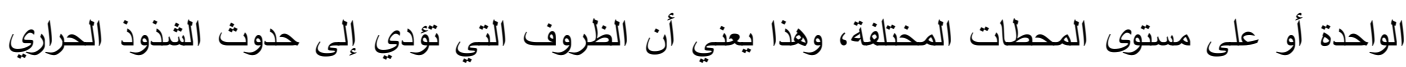

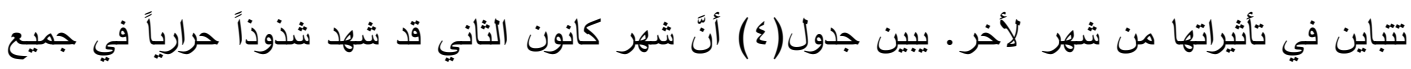

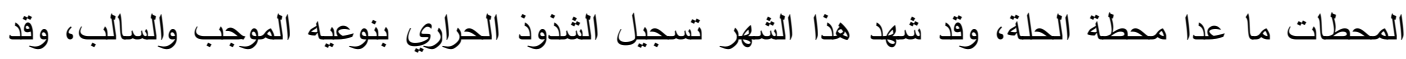

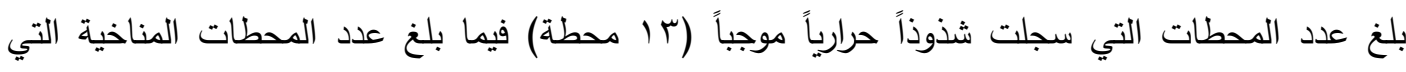

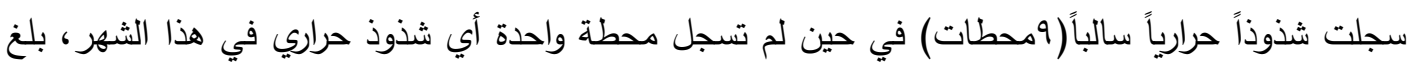

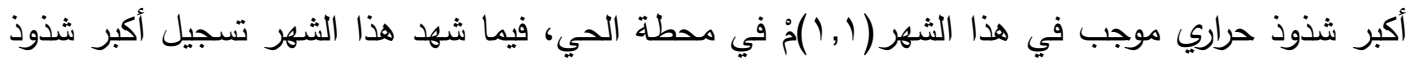
حراري سالب بلغ(-ـ, ())خُ في محطة الرطبة، وفي شهر شباط سجلت جميع محطات الدراسة شذوذاً حرارياً

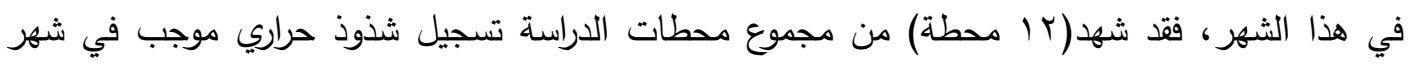

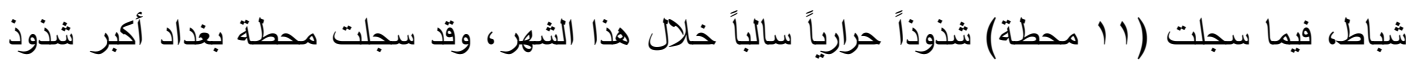

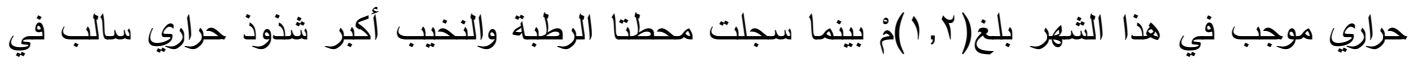

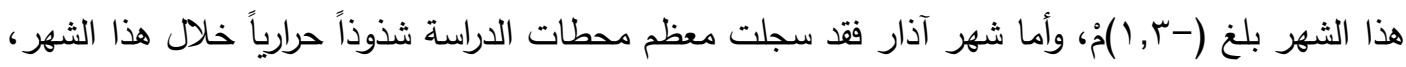

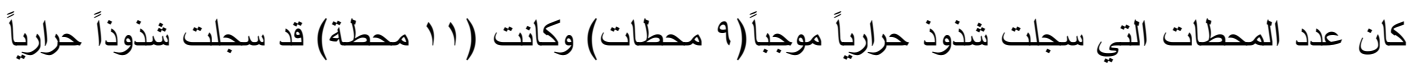
سالباً، فيما لم تسجل (r محطات) أي شذوذ خلال هذا الشهر، كان أكبر شذوذ حراري موجب في شهر آذار

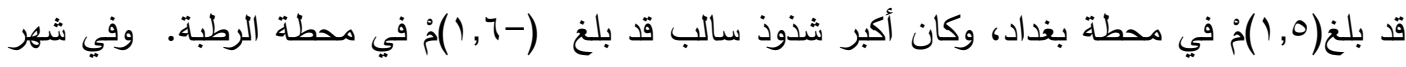

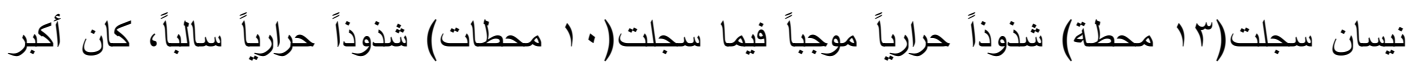

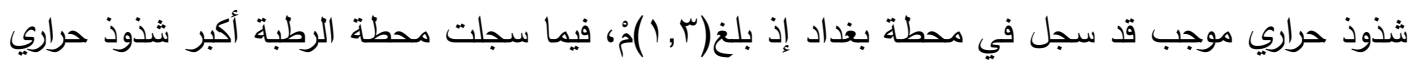

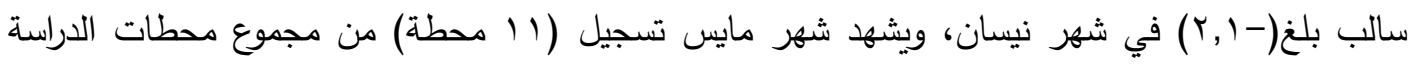

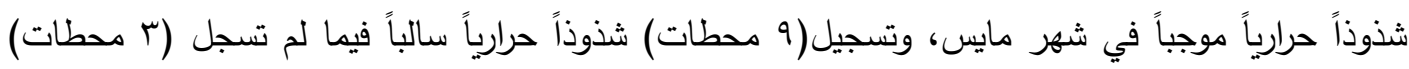

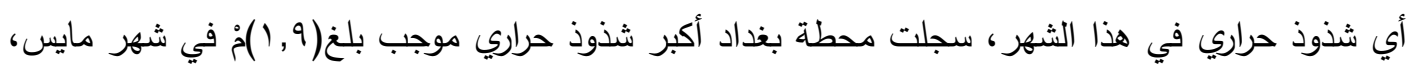

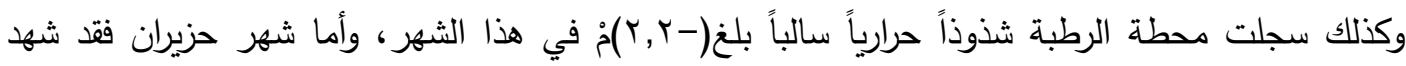

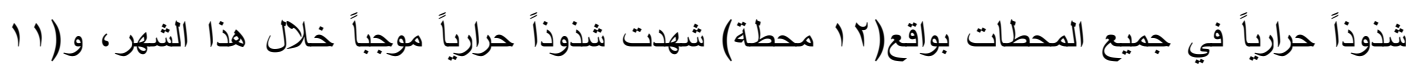

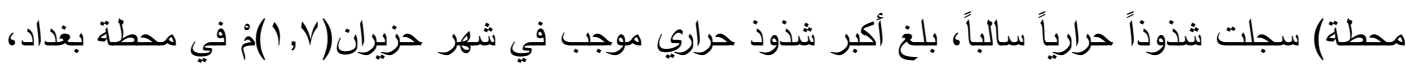

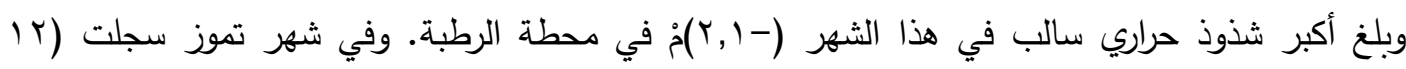

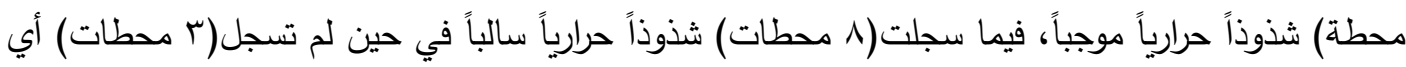


شذوذ حراري في هذا الثهر ، كانت محطة بغداد قد سجلت أكبر شذوذ حراري في هذا الشهر بلغ(V, () )؛، فيما

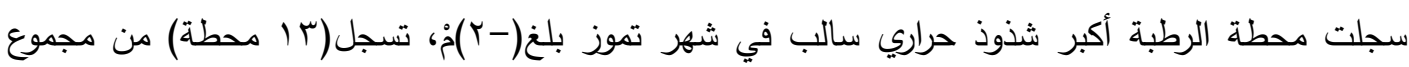

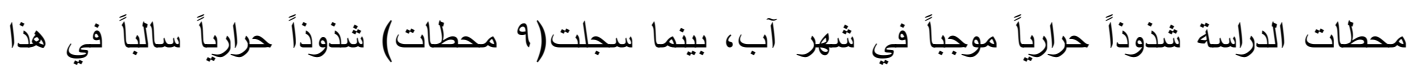

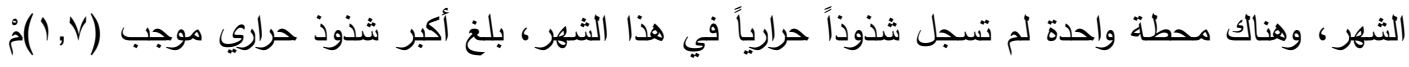

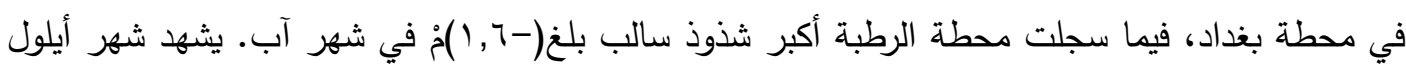

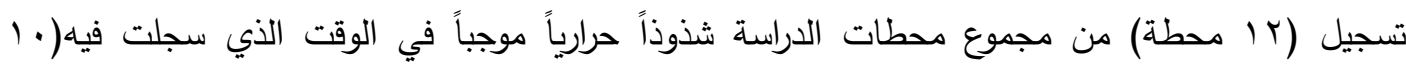

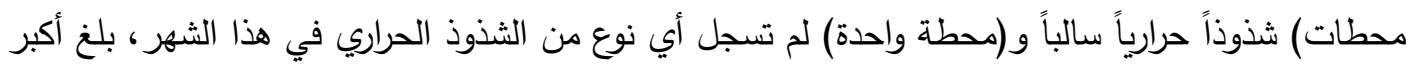

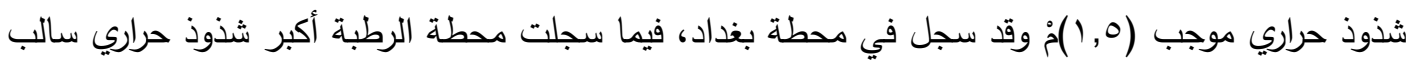

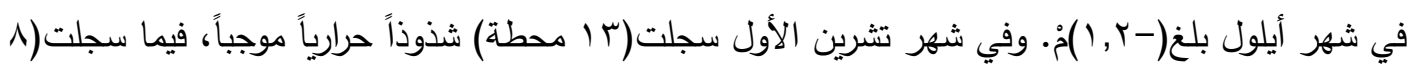
محطات) شذوذاً حرارياً سالباً ولم تسجل محطتان أي شذوذ حراري في هذا الشهر، نجد أنَّ أكبر شذوذ حراري

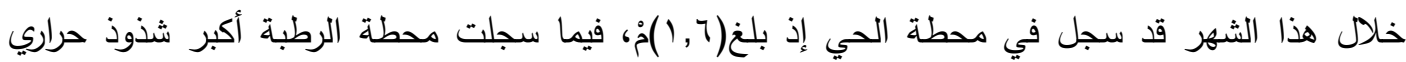

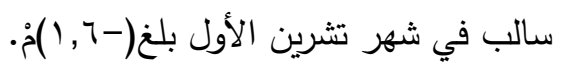

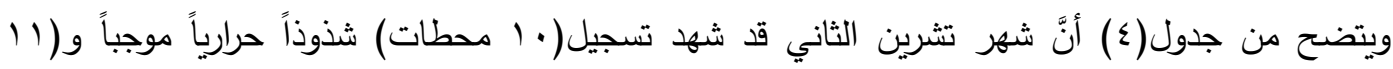
محطة) شذوذاً حرارياً سالباً، فيما لم تسجل محطتان أي شذوذ حراري في هذا الثهر، سجلت فئ محطة الحي

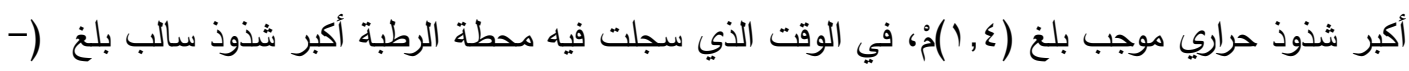

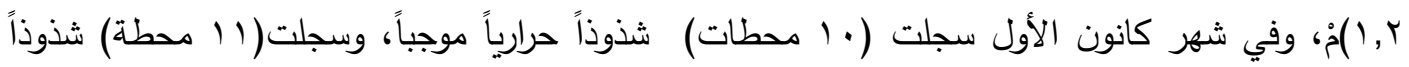

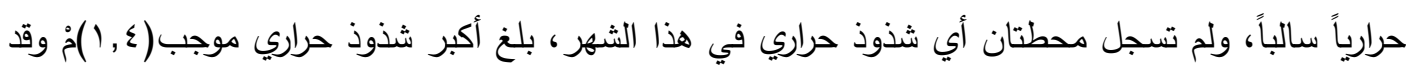

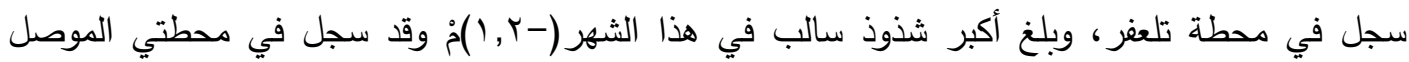




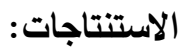

1- يوجد تباين مكاني بين محطات الرصد الجوي المشمولة بالدراسة في تسجيل درجات الثذوذ الحراري في درجات الحرارة الاعتيادية عالمياً ومحلياً. r- شهدت محطات الرصد الجوي المشمولة بالدراسة تسجيل درجات شذوذ حراري موجب في درجات الحات الحرارة

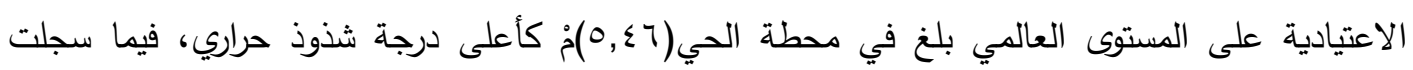
محطة الرطبة (99 ( ·) ) كأقل درجة شذوذ حراري. r- تشهد معظم محطات الدراسة تسجيل درجات شذوذ حراري موجب وسالب في المعدلات السنوية لدرجات الحرارة الاعتيادية على المستوى المحلي، سجلت محطة بغداد أعلى درجة شذوذ حراري في المعدل السنوي

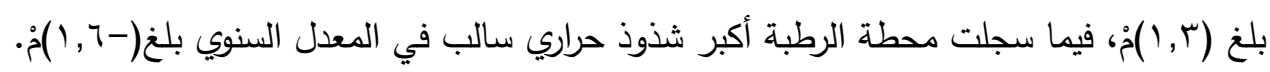

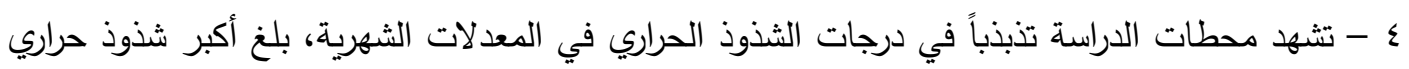

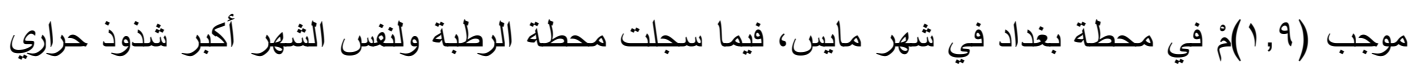

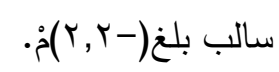

ه- تظهر جميع محطات الدراسة تفوقاً في درجات الثذوذ الحراري المسجل في درجات الحرارة الاعتيادية على المستوى العالمي عن درجات الشذوذ الحراري المسجل على المستوى المحلي.

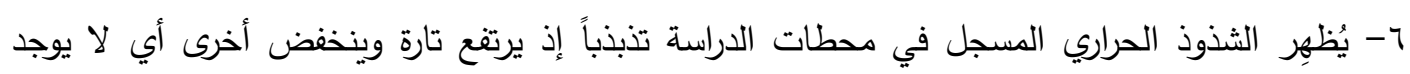
اتجاه ثابت للثذوذ الحراري. 
${ }^{(1)}$ Rajesh PRAKASH, Thermal and neghbourhood, center for Seismolgy, India Meteorological, Anomalies in relation Department, Mausam Bhaean, Lodi Road, to earthquakes in India New Delhi, India,2013, p.2071.

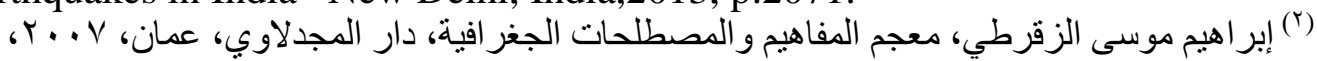

1- الزقرطي، إبراهيم موسى، معجم المفاهيم والمصطلحات الجغرافية، عمّان، V . . Y.

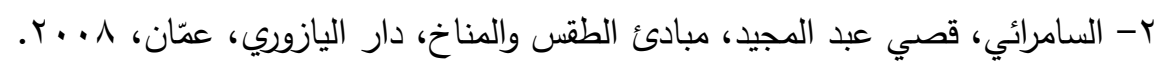

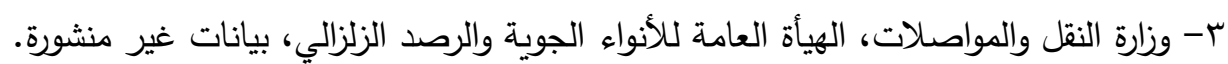

4- Rajesh PRAKASH, Thermal and neghbourhood, center for Seismolgy, India Meteorological, Anomalies in relation Department, Mausam Bhaean, Lodi Road, to earthquakes in India New Delhi, India. 